OPEN ACCESS

Edited by:

Alejandra Victoria Capozzo, Consejo Nacional de Investigaciones Cientificas y Técnicas

(CONICET), Argentina

Reviewed by:

Artur Summerfield,

Institute of Virology and Immunology

(IVI), Switzerland

Suresh H. Basagoudanava, ICAR-Indian Veterinary Research Institute, Bengaluru Campus, India

${ }^{*}$ Correspondence:

James J. Zhu

james.zhu@usda.gov

Jonathan Arzt

Jonathan.arzt@usda.gov

Specialty section:

This article was submitted to

Veterinary Infectious Diseases,

a section of the journa

Frontiers in Veterinary Science

Received: 02 March 2020 Accepted: 15 May 2020

Published: 19 June 2020

Citation:

Zhu JJ, Stenfeldt C, Bishop EA,

Canter JA, Eschbaumer M,

Rodriguez LL and Arzt J (2020)

Mechanisms of Maintenance of

Foot-and-Mouth Disease Virus

Persistence Inferred From Genes

Differentially Expressed in

Nasopharyngeal Epithelia of Virus

Carriers and Non-carriers.

Front. Vet. Sci. 7:340

doi: 10.3389/fvets.2020.00340

\section{Mechanisms of Maintenance of Foot-and-Mouth Disease Virus Persistence Inferred From Genes Differentially Expressed in Nasopharyngeal Epithelia of Virus Carriers and Non-carriers}

\author{
James J. Zhu ${ }^{1 *}$, Carolina Stenfeldtt,2, Elizabeth A. Bishop ${ }^{1}$, Jessica A. Canter ${ }^{1,3}$, \\ Michael Eschbaumer ${ }^{4}$, Luis L. Rodriguez ${ }^{1}$ and Jonathan Arzt ${ }^{1 *}$ \\ 1 USDA-ARS, Foreign Animal Disease Research Unit, Plum Island Animal Disease Center, Orient, NY, United States, \\ ${ }^{2}$ Department of Diagnostic Medicine/Pathobiology, Kansas State University, Manhattan, KS, United States, ${ }^{3}$ Plum Island \\ Animal Disease Center, Oak Ridge Institute for Science and Education (ORISE), Orient, NY, United States, ${ }^{4}$ Institute of \\ Diagnostic Virology, Friedrich-Loeffler-Institut, Greifswald, Germany
}

Foot-and-mouth disease virus (FMDV) causes persistent infection of nasopharyngeal epithelial cells in $\sim 50 \%$ of infected ruminants. The mechanisms involved are not clear. This study provides a continued investigation of differentially expressed genes (DEG) identified in a previously published transcriptomic study analyzing micro-dissected epithelial samples from FMDV carriers and non-carriers. Pathway analysis of DEG indicated that immune cell trafficking, cell death and hematological system could be affected by the differential gene expression. Further examination of the DEG identified five downregulated (chemerin, CCL23, CXCL15, CXCL16, and CXCL17) and one upregulated (CCL2) chemokines in carriers compared to non-carriers. The differential expression could reduce the recruitment of neutrophils, antigen-experienced $T$ cells and dendritic cells and increase the migration of macrophages and NK cells to the epithelia in carriers, which was supported by DEG expressed in these immune cells. Downregulated chemokine expression could be mainly due to the inhibition of canonical NFKB signaling based on DEG in the signaling pathways and transcription factor binding sites predicted from the proximal promoters. Additionally, upregulated CD69, IL33, and NID1 and downregulated CASP3, IL17RA, NCR3LG1, TP53BP1, TRAF3, and TRAF6 in carriers could inhibit the Th17 response, NK cell cytotoxicity and apoptosis. Based on our findings, we hypothesize that (1) under-expression of chemokines that recruit neutrophils, antigen-experienced T cells and dendritic cells, (2) blocking NK cell binding to target cells and (3) suppression of apoptosis induced by death receptor signaling, viral RNA, and cell-mediated cytotoxicity in the epithelia compromised virus clearance and allowed FMDV to persist. These hypothesized mechanisms provide novel information for further investigation of persistent FMDV infection.

Keywords: foot-and-mouth disease virus, FMDV, microarray analysis, persistent infection, pharyngeal epithelia, chemokine expression, NFKB signaling pathways, the Th17 response 


\section{INTRODUCTION}

Foot-and-mouth disease (FMD) is one of the most contagious and economically devastating animal viral diseases. FMD virus (FMDV), a positive-sense single-stranded RNA virus of the family Picornaviridae (genus Aphthovirus), is the etiological agent of the disease. Susceptible hosts include domesticated and wild cloven-hoofed animals. Infection in cattle initiates via the respiratory tract. During primary infection, the virus replicates locally in the nasopharynx or lungs depending on exposure conditions (1-3). The infection subsequently spreads via the bloodstream (viremia) to secondary replication sites causing typical vesicles at specific regions of the oral cavity, feet, and occasionally other sites. Mortality is generally low in adults, but persistent infection can occur for long periods (30 days -5 years) with virus persisting at the primary infection sites (e.g., nasopharynx) in a high percentage $(\sim 50 \%)$ of infected cattle, buffalo and sheep (4-8). Specifically, FMDV persistent replication sites in cattle were localized to the epithelial cells of the dorsal soft palate and pharynx (9) and, more precisely, the follicle-associated epithelia of the nasopharyngeal mucosa $(7,10)$. Although various studies have failed to demonstrate natural transmission from FMDV carrier cattle (8), it has been demonstrated that oropharyngeal fluid from carrier cattle is infectious to naïve cattle (11).

Extensive in-vivo studies have been conducted in order to elucidate the mechanisms of persistent FMDV infection in cattle. Zhang and Alexandersen (12) and Zhang et al. (13) showed that declining rate of FMDV RNA levels in oropharyngeal fluid samples during early infection differed between carriers and non-carriers and proposed that differences in the host's abilities to either clear the virus or to support virus replication may determine the establishment of FMDV persistent infection. There was significantly higher anti-FMDV IgA production in carriers than in non-carriers $(7,14,15)$, indicating antibodies are not effective in complete clearance of FMDV infection. In addition, the lymphocyte proliferative response of peripheral blood mononuclear cells to FMDV antigens was higher in noncarriers than in carriers (16).

Expression levels of a small number of candidate genes such as cytokines $(7,10,17,18)$ and microRNA (19) have been quantitated in FMDV carriers and non-carriers by qRT-PCR. However, these results do not provide detailed mechanisms involved in persistent infection. Broader transcriptomic studies using microarrays have been conducted to obtain genomewide expression profiling of tissues targeted for persistent FMDV infection. A transcriptomic analysis showed that the lungs, susceptible to early infection but not persistent infection, expressed significantly higher levels of TNF cytokines and the associated receptors than the pharyngeal tissues that are susceptible to both primary and persistent FMDV infection (20). However, it is unknown if these same differences between the tissues exist between FMDV carriers and non-carriers. Another transcriptomic study of pharyngeal tissues from carriers and non-carriers indicated that inducible regulatory $\mathrm{T}$ cells (Treg) especially type 1 regulatory $\mathrm{T}$ cells ( $\operatorname{Tr} 1$ ) could play a role in persistent infection based on cytokine and $\operatorname{Tr} 1$-expressed genes being differentially expressed between carriers and noncarriers (21).

Further transcriptomic investigation using RNA prepared from micro-dissected nasopharyngeal epithelia suggested that persistent FMDV infection is associated with compromised apoptosis and a reduced cellular immune response based on some most-differently expressed genes (22). These results could further explain the differences between carriers and noncarriers. Immunohistochemistry analysis using anti-CD3, antiCD8, and anti- $\gamma \delta$ TCR antibodies showed no differences in the numbers of detected cell populations between carriers and non-carriers (22). The current study is a continued analysis of all differentially expressed genes (DEG) from previously published expression data (22) derived from micro-dissected nasopharyngeal epithelium samples of FMDV carriers and noncarriers during the persistent phase of FMDV infection in order to identify additional mechanisms involved. Pathway analyses using the list of all detected DEG show that genes involved in immune cell trafficking were over-represented by DEG including four chemokines known to play key roles in mucosal immunity. Other immune-related DEG support the downregulated chemokine expression in carriers and suggest that reduced recruitment of neutrophils, antigen-experienced $\mathrm{T}$ cells and dendritic cells in carriers could lead to compromised virus clearance and allow FMDV to persist.

\section{METHODS AND MATERIALS}

\section{Gene Expression Data}

The microarray data used in this study and the details of the animal experiments have been reported $(21,22)$. The data were produced using a custom bovine gene expression 60 -mer oligonucleotide microarray designed based on gene expression information displayed on the bovine genome in the UCSC Genome Browser (https://genome.ucsc.edu/index. html). Microarrays and reagents were manufactured by Agilent Technologies (San Jose, CA) and the lab procedures were conducted based on the protocols and equipment recommended by the manufacturer. For comparison of the gene expression levels between carriers and non-carriers, microarray expression data from the micro-dissected pharyngeal epithelia of three carriers (persistently infected by FMDV A24 for $>28$ days) were compared to those from the corresponding micro-dissected tissues of four non-carriers that had cleared FMDV as reported by Stenfeldt et al. (22). For comparison of gene expression between the micro-dissected pharyngeal epithelia samples and whole tissue macerates of nasopharyngeal samples from the corresponding anatomical site, normalized mean expression data from the micro-dissected pharyngeal epithelia of sixteen animals (22) were compared to the data from the whole tissue macerates of nineteen cattle as reported by Eschbaumer et al. (21).

\section{Statistical Analysis}

R scripts implemented with the LIMMA package (23) were used to normalize and analyze the microarray data as previously described (21). All signal intensities (averaged photons per pixel) used in the statistical analysis were $\log _{2}$ transformed. 
Genes differentially expressed between carriers and non-carriers with a false discovery rate (FDR) of 0.10 or smaller and an expression difference of at least $50 \%$ were considered as statistically significant genes in the transcriptomic study. This FDR significance threshold increases the detection power (fewer false negatives/type II errors) with a false positive (type I error) rate of 0.10 in declared DEG, or one false positive in $10 \mathrm{DEG}$, compared to FDR at 0.05 (one in twenty) to balance type I and type II errors. The means of normalized signal intensities (photons per pixel) of ACTA1, ACTA2, and ACTB were used as the internal controls to normalize the expression data to account for differences in the methods of data acquisition between microdissected epithelia (22) and whole tissue macerates (21).

\section{Pathway Analysis}

All bovine genes included in the microarray design were mapped to human reference genes using computer analysis via NCBI BLAST and/or manual annotation by aligning the microarray probe sequences on bovine genome sequences displayed on the UCSC Genome Browser using BLAT program (https:// genome.ucsc.edu/cgi-bin/hgGateway). The list of upregulated and downregulated genes associated with the human Entrez Gene ID was analyzed with Ingenuity Pathway Analysis (IPA) (Qiagen, Maryland) and a NCBI Functional Annotation Bioinformatics Microarray Analysis program (DAVID Bioinformatics Resources version 6.8) to identify the biological pathways significantly overrepresented by DEG. The biological functions of DEG were based on scientific publications obtained from the PubMed website (https://www.ncbi.nlm.nih.gov/pubmed/) listed as cited references or the NCBI Gene database (https://www.ncbi.nlm. nih.gov/gene/) listed as NCBI.

\section{Biological Inferences}

Biological inferences were based on (i) reported biological functions of DEG, (ii) gene expression levels based on microarray averaged signal intensity and (iii) magnitudes (fold difference) of upregulated or downregulated expression, assuming that (1) genes with a higher signal intensity and larger differential expression play a bigger biological role in their gene group and (2) upregulated expression enhances gene activities and vice versa. Differential expression of genes with cell-specific expression was also used to infer the differences in the number of the cells. Genes with no significant differential expression $($ FDR $>0.10)$ but known to play important roles in the relevant biological pathways/processes associated with DEG were also used as references or supporting results for DEG and/or DEG related mechanisms. Probabilities of differential expression at gene levels are listed as $P$-values along with FDR. Genes downregulated or upregulated in carriers compared to non-carriers were expressed as negative and positive values (fold changes), respectively. Multiple DEG involved in a known immune mechanism were used in the formulation of hypothesis. All immune mechanisms known to play roles in virus clearance based on our literature review were considered for candidate mechanisms.

\section{Proximal Promoter Analysis}

The nucleotide sequences up- and down-stream of the gene transcription start sites of four mucosal chemokines (RARRES2/chemerin, CXCL15, CXCL16, and CXCL17) were downloaded from the UCSC Genome Browser (http://genome. ucsc.edu/cgi-bin/). The core promoters were predicted using Neural Network Promoter Prediction (NNPP version 2.2 software) (24). The proximal promoters, 500-bp up-stream and 250-bp down-stream nucleotide sequences of the TATA box or CpG island sequences associated with the transcription starting sites, were used in the prediction of transcription factor binding sites (TFBS) using the TESS 2.0 program (25) and JASPAR database (http://jaspar.genereg.net/downloads/) with a log-odd score of 7.0 or higher (default value at 6.0). Overlapping TFBS for the same transcription factors were counted if the sites differed by at least five nucleotides. AP-1, CREBs, NFKB, IRF3, and STAT1/STAT2 were selected to represent the transcription factors activated by MAPK, NFKB, IRF3 and interferon signaling pathways.

\section{RESULTS}

\section{Pathway Analysis}

There were 1,505 probes with significantly downregulated expression in carriers compared to non-carriers and 1,097 probes with upregulated expression. Among the genes associated with these probes, there were 1,281 downregulated and 951 upregulated genes that could be mapped to human or mouse genes. This gene set including both up- and down-regulated genes was used in the NCBI DAVID and IPA pathway analyses. The KEGG and REACTOME pathway analyses using the NCBI DAVID program showed no significant pathways associated with these DEG. In contrast, pathway analysis with the IPA program detected several significant associations. The top five canonical pathways significantly over-represented by DEG were (1) integrin signaling, (2) Wnt/ $\beta$-catenin signaling, (3) PI3K/AKT signaling, (4) colorectal cancer metastasis signaling, and (5) chronic myeloid leukemia signaling (Figure 1A). The top five upstream regulators were TP53, ESR1, HNF4A, TP63, and beta-estradiol (ordered based on probability) (Figure 1A). None of the top upstream regulator genes were differentially expressed between carriers and non-carriers.

The top five molecular and cellular functions that were significantly associated with the differential expression were (1) cell death and survival, (2) gene expression, (3) cellular assembly and organization, (4) cellular function and maintenance, and (5) cellular development (Figure 1B). The top five inferred physiological system development and function were (1) organism survival, (2) tissue morphology, (3) organism development, (4) hematological system development and function, and (5) immune cell trafficking (Figure 1B). Because cell death/apoptosis and immune cell development, function and trafficking play important roles in immunity against virus infections, DEG involved in these functions were examined in detail.

Among 24 functions associated with immune cell trafficking (Table 1), the top five functions with the lowest $p$-values ranging 
A

Top Diseases and Bio Functions

$\checkmark$ Molecular and Cellular Functions

Name

Cell Death and Survival

Gene Expression

Cellular Assembly and Organization

Cellular Function and Maintenance

Cellular Development

o

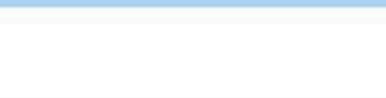

\author{
Cellar Development
}

$\checkmark$ Physiological System Development and Function

Name
Organismal Survival

B

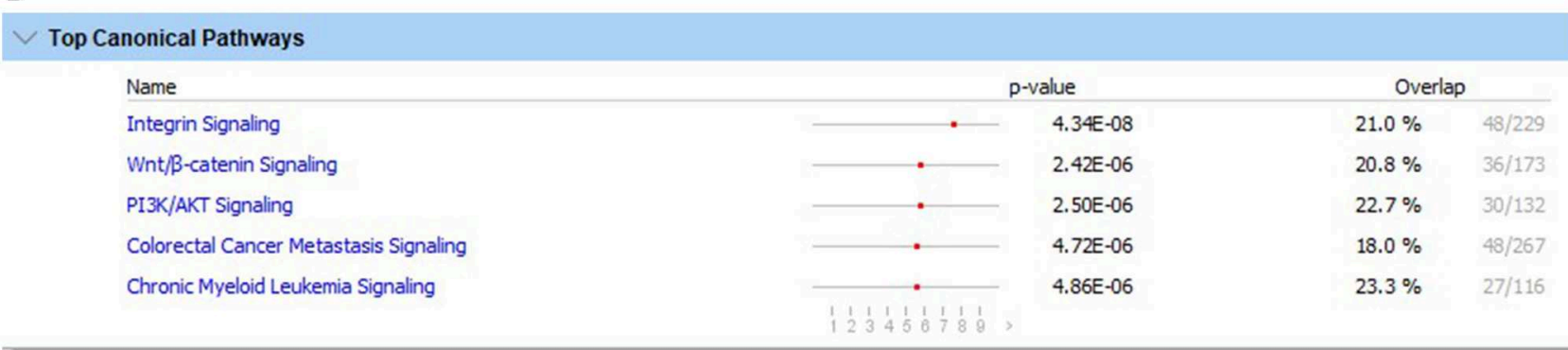



FIGURE 1 | Top five diseases and biological functions (A) and top five canonical pathways and upstream regulators (B) with the lowest likelihoods ( $p$-value) of the associations/overlaps between the differentially expressed gene set (both up- and down-regulated) and the pathways/biological processes by random chances in the Qiagen Ingenuity Pathway Analysis using the list containing ENTREZ numbers and up- and down-regulated DEG. The dots in horizontal lines are the negative log transformation of $p$-values.

from 3.05E-07 to 2.85E-09 were associated with leukocyte movement/infiltration and neutrophil movement. Based on these findings, the differential expression of chemokines was further examined as listed in Table 2, followed by differential expression of the genes supporting or regulating the differential chemokine expression in Table 3. For DEG involved in immune cell development and function, differential expression of cytokines, cytokine signaling pathways and other immune regulatory genes together with their function was analyzed (Tables 46). The DEG involved in apoptosis were evaluated for their potential roles in affecting apoptosis induced by viral RNA, death receptor signaling and cell-mediated cytotoxicity as in Table 7. These DEG were used to formulate the candidate immune mechanisms involved in the maintenance of FMDV persistent infection as shown in Figure 3. The TFBS in proximal promoter regions (Table 8) were predicted as the supporting results of the hypothesis.

\section{Chemokines and the Receptors}

Six chemokine genes were differentially expressed between carriers and non-carriers. Only one of these chemokines (CCL2) was significantly upregulated by 6.8 -fold in carriers compared 
TABLE 1 | The $p$-values of the number (\#) of differentially expressed genes (DEG) in 24 functions (top five with lowest $p$-value in bold fonts) of immune cell trafficking by random chances in the analyses of diseases and functions using Qiagen Ingenuity Pathway Analysis program.

\begin{tabular}{|c|c|c|c|}
\hline Function & $\begin{array}{l}\text { Diseases or functions } \\
\text { annotation }\end{array}$ & $p$-value & \# of DEG \\
\hline Accumulation & Accumulation of neutrophils & 1.13E-04 & 20 \\
\hline \multirow[t]{3}{*}{ Activation } & Activation of leukocytes & 1.33E-05 & 129 \\
\hline & Activation of lymphocytes & 1.67E-05 & 89 \\
\hline & $\begin{array}{l}\text { Activation of mononuclear } \\
\text { leukocytes }\end{array}$ & 2.37E-05 & 92 \\
\hline \multirow[t]{2}{*}{ Adhesion } & Adhesion of immune cells & 5.11E-05 & 70 \\
\hline & $\begin{array}{l}\text { Adhesion of mononuclear } \\
\text { leukocytes }\end{array}$ & 5.85E-05 & 33 \\
\hline \multirow[t]{6}{*}{ Cell movement } & Cell movement of leukocytes & 2.85E-09 & 169 \\
\hline & Cell movement of phagocytes & $1.60 \mathrm{E}-07$ & 121 \\
\hline & Cell movement of neutrophils & 3.05E-07 & 71 \\
\hline & Cell movement of granulocytes & 2.03E-06 & 81 \\
\hline & $\begin{array}{l}\text { Cell movement of mononuclear } \\
\text { leukocytes }\end{array}$ & 5.64E-05 & 93 \\
\hline & $\begin{array}{l}\text { Cell movement of antigen } \\
\text { presenting cells }\end{array}$ & 9.20E-05 & 73 \\
\hline \multirow[t]{2}{*}{ Cell rolling } & Cell rolling of leukocytes & 3.90E-05 & 20 \\
\hline & Cell rolling of phagocytes & 1.09E-04 & 11 \\
\hline \multirow[t]{4}{*}{ Cellular infiltration } & Cellular infiltration by leukocytes & 7.11E-07 & 89 \\
\hline & $\begin{array}{l}\text { Cellular infiltration by } \\
\text { phagocytes }\end{array}$ & 4.18E-06 & 63 \\
\hline & Infiltration by neutrophils & 7.32E-05 & 39 \\
\hline & $\begin{array}{l}\text { Cellular infiltration by } \\
\text { macrophages }\end{array}$ & $1.08 \mathrm{E}-04$ & 39 \\
\hline \multirow[t]{3}{*}{ Chemotaxis } & Chemotaxis of leukocytes & $1.87 \mathrm{E}-05$ & 73 \\
\hline & Chemotaxis of phagocytes & $6.74 \mathrm{E}-05$ & 60 \\
\hline & Chemotaxis of neutrophils & $1.11 \mathrm{E}-04$ & 35 \\
\hline \multirow[t]{2}{*}{ Homing } & Homing of leukocytes & 6.63E-07 & 82 \\
\hline & $\begin{array}{l}\text { Homing of mononuclear } \\
\text { leukocytes }\end{array}$ & 8.38E-05 & 44 \\
\hline Migration & Leukocyte migration & 1.23E-08 & 196 \\
\hline
\end{tabular}

to non-carriers (Table 2). CCL2 has chemotactic activity for inflammatory monocytes and NK cells (26-28). Additionally, higher expression of C5AR1, CD16, CD300A, CD300LD, GZMA, GZMM, KLRB1, MMD, and NCR2 including an unannotated KLR in carriers compared to non-carriers (Table 3) supports increased migration of monocytes and NK cells into the persistently infected epithelia. Monocyte to macrophage differentiation-associated (MMD) is highly expressed in mature differentiated macrophages after migration to tissues but is absent in monocytes (106). CD16, specifically expressed on NK cells and some monocytes/macrophages, can activate antibody directed cell-mediated cytotoxicity $(54,107)$, whereas KLR receptors and NCR2 are receptors highly expressed on NK cells (56). Granzymes are cytotoxicity effectors expressed in cytotoxic $\mathrm{T}$ cells and NK cells (108) and Treg cells (109). C5AR1 is expressed in myeloid cells including macrophages and granulocytes (37). CD300 receptors which are mainly expressed on myeloid cells play a fundamental role in immune regulation (61).
The expression of five chemokines (CCL23, CXCL15, CXCL16, CXCL17, and RARRES2, also named chemerin) was significantly downregulated in carriers compared to non-carriers by 2.5 - to 17.9 -fold (Table 2). These chemokines all have chemotactic activities for antigen presenting cells, antigenexperienced T cells, monocytes, NKT cells and/or neutrophils (29-36). Chemerin, CXCL15, CXCL16, and CXCL17 were expressed at higher levels by 2.2-, 5.0-, 6.1-, and 1.7-fold, respectively, in the micro-dissected epithelia than in the whole tissues (Figure 2), indicating epithelium-specific expression. The differential expression of chemokines could potentially result in reduced recruitment of dendritic cells, antigen-experienced $\mathrm{T}$ cells and neutrophils to the nasopharyngeal epithelium of the carriers compared to the non-carriers. This hypothesis was further supported by analysis of DEG associated with expression of the chemokines of interest (Table 3).

Two chemokine receptors, CXCR1 and CXCR2, known to be predominately expressed on neutrophils $(27,40)$, were expressed at significantly lower levels in carriers than in noncarriers (Table 3). Cathepsins are components of neutrophil granules, and the expression of three cathepsins (CTSC, CTSF, and CTSV) was significantly lower in carriers than in noncarriers. CD38 is important for neutrophil migration $(38,39)$, whereas RGS5 inhibits neutrophil chemotaxis and trafficking (41). CD38 expression was lower and RGS5 was higher in carriers than in non-carriers. The expression of C3, an important component for activation of the classical and alternative complement activation pathways that lead to production of $\mathrm{C} 5 \mathrm{a}$ to recruit neutrophils (110), was downregulated by 15- fold in carriers compared to non-carriers (Table 3). All ELR+ CXCLs have chemotactic activity for neutrophils $(27,32)$. Although only CXCL15 showed significant differential expression, the total normalized signal intensity of six bovine ELR + CXCLs including CXCL1, CXCL2, CXCL3, CXCL5, CXCL8 and CXCL15 was 2.4 times lower in carriers than non-carriers (Table 2), further supporting lower expression of neutrophil-recruiting chemokines in carriers.

Other DEG supported reduced recruitment of antigenexperienced $\mathrm{T}$ cells and dendritic cells in nasopharyngeal epithelium of FMDV carriers (Table 3). CD44 is a cell marker for antigen-experienced $\mathrm{T}$ cells including $\mathrm{T}$ effector, central memory $\mathrm{T}, \mathrm{T}$ effector memory and $\mathrm{T}$ resident memory cells but not naïve $\mathrm{T}$ cells (43). CD44 expression was downregulated by nearly threefold in carriers compared to non-carriers. There were three effector T-cell-expressed genes (CD27, CD73 and CD244 $(42,44-48)$ with $\geq 4$.4-fold decreased expression in carriers. LAT, IKT and two TRBC2 (T cell receptor beta constant 2) involved in TCR signaling (49-51) displayed >3-fold downregulated expression in carriers. By contrast, genes highly expressed on naïve $T$ and natural intraepithelial lymphocytes such as CD45R, CD62L, and CD161 (52, 53, 55) were expressed significantly higher in carriers than in non-carriers. The expression of $\mathrm{T}$ cell marker genes, CD2, CD3D, CD4, CD8A, and CD8B was not significantly different. Dendritic cells express CLEC9A/DNGR1, CD276, VISTA and VTCN1 (57-60). These four genes were expressed at significantly lower levels in carriers than in noncarriers. These results suggest a reduced recruitment of dendritic 
TABLE 2 | Mean expression levels (microarray signal intensity, MSI), false discovery rates (FDR), fold differences (+ and - values as up- and down-regulated in carriers compared to non-carriers, respectively) and chemotactic activities of chemokine genes differentially expressed between the nasopharynx epithelia of carriers and non-carriers.

\begin{tabular}{|c|c|c|c|c|c|}
\hline Gene & MSI & FDR & Fold & Chemotactic activity $^{a}$ & References \\
\hline CCL2 & 841 & 0.03 & 6.8 & Inflammatory monocytes and NK cells & $(26-28)$ \\
\hline CCL23 & 422 & 0.10 & -17.9 & Resting T cells, monocytes \& neutrophils & $(29)$ \\
\hline Chemerin & 1188 & 0.02 & -5.7 & Immature DC and macrophages (M $\phi)$ & $(30,31)$ \\
\hline CXCL15 & 525 & 0.08 & -7.6 & Neutrophils & $(32)$ \\
\hline CXCL16 & 13128 & 0.04 & -2.5 & Activated CD8+/CD4+ T, IEL and NKT cells & $(33-35)$ \\
\hline $\mathrm{CXCL} 17$ & 3028 & 0.01 & -3.5 & Immature DC, M $\phi$, CD8+ Tem and Trm cells & $(36)$ \\
\hline $\mathrm{ELR}+\mathrm{CXCLs}{ }^{\mathrm{b}}$ & 2530 & $\mathrm{n} / \mathrm{a}$ & -2.4 & Neutrophil > monocyte, NK, CD8+ T cells & $(27)$ \\
\hline
\end{tabular}

${ }^{a} D C$, dendritic cells; M , macrophages; IEL, intraepithelial lymphocytes; NKT, natural killer T cells; Tem, memory T effector; Trm, resident memory T cells.

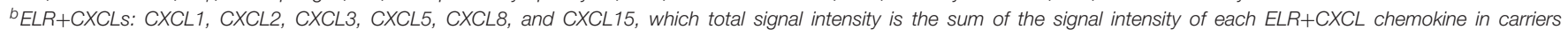
and non-carriers.

cells and antigen-experienced T cells within the nasopharyngeal epithelium of FMDV carriers.

\section{Cytokines and the Receptors}

Ten cytokines belonging to interferon (IFNA and IFNL), IL-1 (IL1A, IL33, and IL36A), IL-2- (IL7 and IL15) or TNF (TNF, TNFSF10, and TNFSF15) families were expressed at significantly higher levels in carriers than in non-carriers (Table 4). All significantly upregulated cytokines were proinflammatory or immune-stimulatory except IL33. IL33 activates Th1 and Th2 cells, group 2 innate lymphoid cells, and CD8+ T cells, and it also plays a key role in suppressing Th17 and promoting Treg (95). Among the significant cytokines, TNF and IL33 were expressed at the highest levels and were the most upregulated (approximately 15-fold). Other cytokines significantly upregulated by $\sim 6$ - to 10 -fold were IL1A, IL7, IL36A, and TNFSF15, whereas IFNA, IFNL, IL15, and TNFSF10 were expressed at levels 1.5- to 2.5-fold higher in carriers than in non-carriers (FDR $\leq 0.1$ ). The signaling of IL-1 cytokines can be inhibited by soluble IL1RAP (sIL1RAP, an alternative 3' end transcript) (111), and the sIL1RAP expression level was significantly higher in carriers than in non-carriers (the only differently expressed receptor of the cytokine DEG) was not differentially expressed between carriers and noncarriers. The expression of a receptor (IL10RA) of IL10, an immunosuppressive cytokine (112), was nearly 3-fold higher in carriers than in non-carriers. These results suggest that 15-fold upregulation of IL33 could significantly suppress the Th17 response.

There are also several cytokine genes differentially expressed at gene levels $(P \leq 0.05)$. IL1RN is an IL-1 antagonist. IL6 and IL23 are important cytokines stimulating Th17 cell differentiation (113). IL22 plays a key role in mucosal immunity by stimulating inflammatory responses and inducing S100s and defensin expression (94). EBI3 or IL35B is a part of an immune inhibitory cytokine, IL35. The expression of IL1RN, IL6, IL22, IL23A, and EBI3/IL35B was upregulated in carriers at $p \leq 0.05$. Among the receptors of the differentially expressed cytokines, IL6R, IL15R, and IL1RL1 (ST2, IL33 receptor) were expressed at higher levels $(p \leq$
0.02) in carriers than in non-carriers, whereas IL12RB1 (a part of IL23 receptors) was expressed at a lower level ( $p$ $=0.02 ; \mathrm{FDR}=0.19)$ in carriers than in non-carriers. The expression of IL10 was different between carriers and noncarriers.

\section{Signal Transducing Genes}

There were several DEG in interferon, IRF3, MAPK and $\mathrm{NF \kappa B}$ signaling pathways that could negatively impact cytokine signaling in carriers (Table 5). Toll-like receptor 6 (TLR6) was expressed 7.7-fold lower in carriers compared to noncarriers. The expression of ATK1 and AKT3, which are involved in interferon signaling $(63,114)$, were significantly lower in carriers than in non-carriers. There were eight signal transducers (MAP3K9, MAPK3, MAPK8IP1, MAPKAPK3, MAPKAPK5, TAB1, TRAF3, and TRAF6) and two transcription factors (CREB5 and NFKB2) in the IRF3, MAPK and NFKB signaling pathways (64-66), which expression levels were significantly downregulated in carriers compared to non-carriers (Table 5). However, one kinase, CHUK/IKK $\alpha$ essential for non-canonical NFKB signaling pathway but dispensable for canonical NFKB signaling pathway (67) was expressed at a significantly higher level (3.1-fold) in carriers than in non-carriers, whereas the expression of two other kinases (IKKB and IKKG) crucial for the canonical pathway was downregulated by $>3$-fold at close to a significant level (FDR $=0.12$ and 0.15 ), suggesting the differential expression was in favor of activation of non-canonical NFKB signaling pathway.

Interestingly, four signaling enhancers of the IRF3 and/or canonical NFKB pathways, OTUB1 (68), RNF128 (69), TGFB2OT1 (70) and TRIM52 (71) were expressed at significantly lower levels in carriers than in non-carriers. By contrast, four inhibitors, HIVEP2 (72), NKIRAS1 (73), NLK (74) and NKRF (75) of the canonical NFKB signaling pathway were expressed 2.8 to 11.8-fold higher in carriers than in non-carriers. Additionally, two immune inhibitory microRNAs, MIR221 $(77,78)$ and MIR503HG (79) as well as one proinflammatory one, MIR155, which also has both anti-apoptotic activity $(115,116)$ and an inhibitory effect on interferon signaling (76), were upregulated 


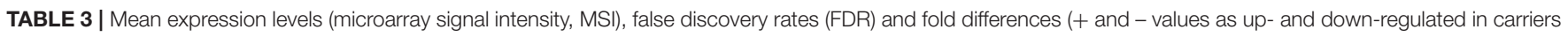
compared to non-carriers, respectively) of differentially expressed genes supporting decreased numbers of neutrophils, antigen-experienced T cells and dendritic cells and increased number of naïve and natural intraepithelial lymphocytes.

\begin{tabular}{|c|c|c|c|c|c|c|}
\hline Group & Gene & MSI & FDR & Fold & Expressing cells/functions ${ }^{a}$ & References \\
\hline \multirow[t]{8}{*}{ Neutrophil } & C3 & 16129 & 0.03 & -15 & Neutrophil chemoattractant C3a & $(37)$ \\
\hline & CD38 & 241 & 0.02 & -8.1 & Neutrophils/migration & $(30,38,39)$ \\
\hline & CTSC & 23238 & 0.04 & -2.6 & Neutrophils/granule component & $\mathrm{NCBI}$ \\
\hline & CTSF & 1084 & 0.01 & -11.7 & & \\
\hline & CTSV & 5645 & 0.04 & -3.4 & & \\
\hline & $\mathrm{CXCR} 1$ & 102 & 0.09 & -2.3 & Neutrophils/ELR+ CXCL receptor & $(27,40)$ \\
\hline & CXCR2 & 259 & 0.06 & -3.8 & & \\
\hline & RGS5 & 426 & 0.06 & 5.4 & Neutrophils/migration inhibitor & $(41)$ \\
\hline \multirow[t]{15}{*}{ Antigen-specificT cell } & CD27 & 556 & 0.00 & -4.4 & CD8+ effector $T$ cells & $(42)$ \\
\hline & CD44 & 13684 & 0.07 & -2.9 & Antigen-experienced T cells & $(43)$ \\
\hline & CD73 & 1244 & 0.05 & -17.0 & CD8+ effector T cells and Treg & $(44-46)$ \\
\hline & CD244/2B4 & 450 & 0.03 & -4.9 & NK cells and CD8+ effector T cells & $(47,48)$ \\
\hline & LAT & 248 & 0.02 & -6.9 & T cells/TCR signaling & $(49-51)$ \\
\hline & ITK & 1469 & 0.09 & -3.5 & T cells/TCR signaling & $(51)$ \\
\hline & TRBC2 & 1074 & 0.09 & -5.1 & $\mathrm{~T}$ cells/TCR beta chain & $(49-51)$ \\
\hline & TRBC2 & 1113 & 0.05 & -3.4 & & \\
\hline & CD45R & 360 & 0.01 & 14.3 & Naïve T cells & $(52,53)$ \\
\hline & SELL/CD62L & 1747 & 0.01 & 4.3 & Naïve T and central Tm cells & $(52,53)$ \\
\hline & CD2 & 716 & 0.31 & -5.3 & T cells & $\mathrm{NCBI}$ \\
\hline & CD3D & 1700 & 0.59 & 2.0 & T cells & $\mathrm{NCBI}$ \\
\hline & CD4 & 420 & 0.72 & -1.4 & CD4+ T cells & $\mathrm{NCBl}$ \\
\hline & CD8A & 1601 & 0.82 & -1.5 & CD8+ T and IEL & $\mathrm{NCBI}$ \\
\hline & CD8B & 120 & 0.65 & 1.8 & CD8+ $\mathrm{T}$ cells & $\mathrm{NCBI}$ \\
\hline \multirow[t]{7}{*}{ Antigen-non-specific T cells } & CD16 & 89 & 0.02 & 2.1 & NK cells and monocytes & $(54)$ \\
\hline & GZMA & 91 & 0.05 & 4.6 & NK cells, cytotoxic T cells, Treg & $\mathrm{NCBI}$ \\
\hline & GZMM & 66 & 0.08 & 2.5 & & \\
\hline & KLRB1/CD161 & 111 & 0.09 & 4.0 & NK cells and natural IEL & $(55)$ \\
\hline & KLR (unknown) & 164 & 0.00 & 3.8 & & \\
\hline & NCR2 & 625 & 0.00 & 10.4 & NK cell receptors & $(56)$ \\
\hline & NCR3 & 243 & 0.27 & 4.4 & & \\
\hline \multirow[t]{4}{*}{ Dendritic cells } & CD276/B7-H3 & 228 & 0.04 & -2.7 & Antigen presenting cells & $(57)$ \\
\hline & CLEC9A/DNGR1 & 93 & 0.07 & -2.2 & DC/cross-presentation & $(58)$ \\
\hline & VISTA/B7-H5 & 1182 & 0.05 & -5.0 & Antigen presenting cells & $(59)$ \\
\hline & VTCN1/B7-H4 & 2468 & 0.04 & -5.0 & Antigen presenting cells & $(60)$ \\
\hline \multirow[t]{4}{*}{ Macro-phages } & C5AR1 & 62 & 0.01 & 2.0 & Myeloid cells, Mф M1 activation & $(37)$ \\
\hline & CD300A & 66 & 0.02 & 1.6 & Macrophages & $(61)$ \\
\hline & CD300LD & 154 & 0.06 & 2.5 & Macrophages & $(61)$ \\
\hline & MMD & 914 & 0.03 & 9.3 & Macrophages & (62) \\
\hline
\end{tabular}

${ }^{a} D C$, dendritic cells; IELs, intraepithelial lymphocytes; M , macrophage; TCR, T cell receptor.

in carriers. These findings suggest that the interferon, IRF3, MAPK and especially canonical NFKB signaling pathways could be negatively impacted by the differential gene expression during persistent FMDV infection.

\section{Immune Cell-Associated Genes}

MFSD6 recognizes certain MHC-I molecules and mediates MHC-I restricted killing by macrophages (117). The expression levels of MFSD6and a non-classical MHC-I were 3.9 and 7.7 times lower in carriers compared to non-carriers (Table 6).
Similarly, a ligand (NCR3LG1) of NK cell receptor 3 (NCR3) (80) was expressed at a significantly lower level in carriers than in non-carriers, whereas a NK cell cytotoxicity inhibitory soluble ligand (NID1) of NCR2 (81) was significantly upregulated by 12.1-fold in carriers vs. non-carriers. This differential expression could inhibit macrophage- and NK cell-mediated cytotoxicity in carriers.

Intraepithelial lymphocytes (IEL) are heterogenous $\mathrm{T}$ cells reside within the epithelial layer of mucosal and barrier tissues. CD69 is a receptor expressed by several subsets of tissue 


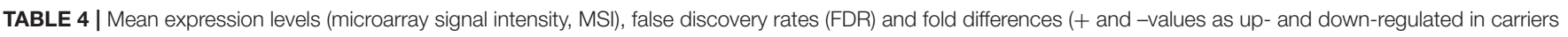
compared to non-carriers, respectively) of cytokines and the receptors differentially expressed between the nasopharynx epithelia of carriers and non-carriers.

\begin{tabular}{|c|c|c|c|c|c|c|}
\hline Gene group & Gene & MSI & $p$-value & FDR & FD & Function \\
\hline IFN, Type 1 & IFNA & 70 & & 0.10 & 1.5 & Anti-viral cytokines \\
\hline \multirow[t]{6}{*}{ IL-1 family } & IL1A & 102 & & 0.04 & 6.0 & Proinflammatory \\
\hline & IL36A & 104 & & 0.00 & 9.9 & \\
\hline & IL1RN & 5405 & 0.02 & 0.18 & 1.8 & Anti-inflammatory or stimulate Treg cells \\
\hline & IL33/IL1F11 & 578 & & 0.02 & 14.7 & \\
\hline & IL1RL1/ST2 & 55 & 0.02 & 0.18 & 2.2 & \\
\hline & sIL1RAP & 115 & & 0.07 & 4.2 & \\
\hline \multirow[t]{4}{*}{ IL-2 family } & IL7 & 139 & & 0.04 & 8.2 & T \& B cell development \\
\hline & IL7R & 3099 & 0.07 & 0.33 & 2.1 & IL7 receptor \\
\hline & IL15 & 100 & & 0.06 & 1.7 & $\uparrow N K \&$ CD8+ T cells \\
\hline & IL15R & 146 & 0.01 & 0.12 & 3.3 & IL-15 receptor \\
\hline \multirow[t]{4}{*}{ IL-10 family } & $\mathrm{IFNL}$ & 184 & & 0.04 & 2.5 & Anti-viral cytokines \\
\hline & IL10 & 112 & 0.92 & 0.98 & -1.1 & Immune inhibition \\
\hline & IL10RA & 3866 & & 0.06 & 2.9 & \\
\hline & IL22 & 42 & 0.04 & 0.25 & 1.6 & 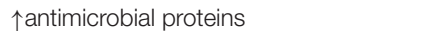 \\
\hline \multirow[t]{3}{*}{ TNF family } & TNF & 494 & & 0.00 & 15.0 & Inflammation/apoptosis \\
\hline & TNFSF10/TRAIL & 305 & & 0.04 & 2.3 & Apoptosis \\
\hline & TNFSF15/TL1A & 401 & & 0.10 & 7.1 & Inflammation/apoptosis \\
\hline \multirow[t]{7}{*}{ Th17-related } & IL6 & 139 & 0.02 & 0.19 & 1.3 & 个Th17 differentiation \\
\hline & IL6R & 2696 & 0.01 & 0.13 & 4.5 & IL-6 receptor \\
\hline & IL23A & 540 & 0.01 & 0.11 & 4.2 & $\uparrow$ Th17 differentiation \\
\hline & IL12RB1 & 387 & 0.02 & 0.19 & -7.0 & IL-23 receptor \\
\hline & $\| 17 A$ & 161 & 0.12 & 0.34 & 3.4 & $\uparrow$ Th17 response \\
\hline & IL17F & 227 & 0.15 & 0.49 & -1.9 & \\
\hline & IL17RA & 951 & & 0.06 & -2.4 & IL17A and IL17F receptor \\
\hline Anti-inflammatory & EBI3/IL35B & 83 & 0.02 & 0.21 & 3.6 & Immune suppression \\
\hline
\end{tabular}

resident immune cells such as IEL. It plays a key role in regulating $\mathrm{T}$ cell differentiation and activities depending on the cells [86]. Three probes of CD69 consistently showed $\sim 5$-fold upregulated expression $(\mathrm{FDR}=0.00)$ in carriers compared to non-carriers (Table 6). On the other hand, two genes (CD27 and CD244), playing important roles in activating $\mathrm{T}$ cells especially CD8+ cytotoxic T cells and NK cells $(42,47,48)$, were expressed at significantly lower levels in carriers. Additionally, TNFRSF19 Inhibits TGF $\beta$ Signaling (84) and TGF $\beta$ signaling suppressed $\mathrm{T}$ cell cytotoxicity and promote immune tolerance (85), whose expression was significantly downregulated in carriers. The differential expression of these genes could inhibit IEL cytotoxicity.

T-bet is required for the development of CD8aa+ IEL $(88,89)$. T-bet expression increases in non-CD4 $+\mathrm{T}$ cell-helped resident memory T cells, which suppresses CD103 expression (87). The expression of T-bet was significantly upregulated in carriers compared to non-carriers, whereas CD103 expression was downregulated $(P=0.03)$. A probe of bovine immunoglobulin delta heavy chain constant region mRNA (NCBI accession \#: AF411240) displayed significant 2.3-fold increased signal intensity in carriers than in non-carriers, indicating more of $\gamma \delta$ $\mathrm{T}$ cells in the epithelium of carriers than in non-carrier. $\gamma \delta \mathrm{T}$ cells are known to have regulatory functions in mucosal immunity
(86). These results indicate that $\mathrm{T}$ cells in the epithelium (also called as IEL), especially $\gamma \delta \mathrm{T}$ cells, might play a role in FMDV persistent infection.

RORC is a Th17-specific transcription factor. RORC and STAT3 promotes Th17 differentiation (90). TIAM1 forms a complex with RORC in the nuclear compartment of Th17 cells and together they bind and activate the IL17 promoter (91). TIAM1 expression was downregulated by 20.8 -fold in carriers compared to non-carriers, whereas the expression levels of RORC and STAT3 were lower in carriers than in non-carriers $(P \leq 0.03)$. On the other hand, CD69, ETS1, IL33 and STAT5 are negative regulators of Th17 differentiation and activity $(90,92,118,119)$. The expression levels of these four genes were 4.4- to 14.7fold higher in carriers than in non-carriers. Th17 cells increase the expression of IL33 receptor (IL1RL1) upon inflammation in mucosa and IL33 induces acquire immunosuppressive properties in Th17 cells (93). IL1RL1 expression was higher in carriers than in non-carriers $(P=0.02)$. These results suggest that the Th17 response could be suppressed in carriers.

$\operatorname{Tr} 1$ is an antigen-specific FOXP3- regulatory $\mathrm{T}$ cell and CD49B and PRDM1 are Tr1 markers $(96,97)$. CD49B and PRDM1 expression was significantly higher in carriers than in non-carriers (Table 6). Two genes associated with Tr1 differentiation (EBI3 and MAF) $(96,120)$ were also expressed 


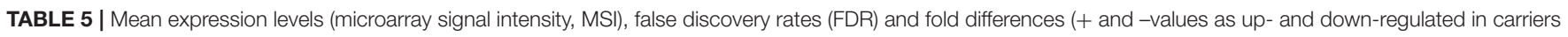
compared to non-carriers, respectively) of differentially expressed genes in interferon, IRF3, MAP, and NFKB signaling pathways.

\begin{tabular}{|c|c|c|c|c|c|c|}
\hline Gene group & Gene & MSI & FDR & Fold & Function & References \\
\hline TLR & TLR6 & 147 & 0.05 & -7.7 & Activate NFKB, IRFs and MAPKs & $\mathrm{NCBI}$ \\
\hline \multirow[t]{13}{*}{ Signal transducers } & AKT1 & 2378 & 0.05 & -2.5 & Enhance interferon signaling \& NFKB activation & $(63,64)$ \\
\hline & AKT3 & 1000 & 0.01 & -6.3 & & \\
\hline & $\mathrm{CHUK} / \mathrm{IKK} \alpha$ & 326 & 0.06 & 3.1 & Non-canonical NFкB signaling & $(65)$ \\
\hline & $\mathrm{IKBKB} / \mathrm{IKK} \beta$ & 6116 & 0.12 & -4.3 & Canonical NFKB signaling & \\
\hline & $\mathrm{IKBKG} / \mathrm{IKK} \gamma$ & 1693 & 0.15 & -3.3 & Canonical NFKB signaling & \\
\hline & MAP3K9 & 767 & 0.01 & -5 & MAP kinases in MAP signaling pathways & NCBI (66) \\
\hline & MAPK3 & 1810 & 0.06 & -10.6 & & \\
\hline & MAPK8IP1 & 168 & 0.03 & -1.8 & & \\
\hline & MAPKAPK3 & 20022 & 0.09 & -1.8 & & \\
\hline & MAPKAPK5 & 537 & 0.08 & -5.1 & & \\
\hline & TAB1 & 1366 & 0.03 & -2.9 & Signaling transducers in IRF3, MAP and NFKB signaling pathways & $(64-67)$ \\
\hline & TRAF3 & 1980 & 0.02 & -3.4 & & \\
\hline & TRAF6 & 267 & 0.00 & -12.4 & & \\
\hline \multirow[t]{4}{*}{ NFKB signaling enhancers } & OTUB1 & 2939 & 0.01 & -4.9 & Specific ubiquitin iso-peptidase & $(68)$ \\
\hline & RNF128 & 1467 & 0.00 & -4.3 & E3 ubiquitin ligase & (69) \\
\hline & TGFB2-OT1 & 226 & 0.05 & -3.6 & Activate NFKB RELA & $(70)$ \\
\hline & TRIM52 & 128 & 0.03 & -3.1 & Enhance NFKB signaling & $(71)$ \\
\hline \multirow[t]{4}{*}{ NFкB signaling inhibitors } & HIVEP2 & 1033 & 0.05 & 11.8 & Inhibit NFאB in DNA binding & $(72)$ \\
\hline & NKIRAS1 & 318 & 0.03 & 4.6 & Inhibit IKK $\beta$ activity & (73) \\
\hline & NLK & 375 & 0.03 & 9.7 & Inhibit co-activators of $\mathrm{NF}_{\kappa} \mathrm{B}$ & $(74)$ \\
\hline & NKRF & 147 & 0.07 & 2.8 & Nuclear inhibitor of $\mathrm{NF}_{\kappa} \mathrm{B}$ & $(75)$ \\
\hline \multirow[t]{3}{*}{ Transcription factors } & CREB5 & 264 & 0.00 & -22.5 & Co-activated with NFאB by TLR & $(65,66)$ \\
\hline & NFKB2 & 2376 & 0.03 & -4.1 & Non-canonical NFкB signaling & $(65)$ \\
\hline & RELA & 4183 & 0.08 & 3.8 & Canonical NFKB signaling & $(65)$ \\
\hline \multirow[t]{3}{*}{ miRNAs } & MIR155HG & 219 & 0.00 & 12.7 & Suppress interferon signaling & $(76)$ \\
\hline & MIR221 & 540 & 0.05 & 2.9 & $\downarrow$ IFN $\beta$ expression \& LPS signaling & $(77,78)$ \\
\hline & MIR503HG & 165 & 0.05 & 2.4 & Inhibit NFKB signaling & $(79)$ \\
\hline
\end{tabular}

higher in carriers $(p=0.02$ and 0.1 , respectively). FOXP3 and ThPOK are a CD4+ $\mathrm{T}$ cell-specific and Treg-specific transcription factors, respectively. FOXP3+ Treg cells lose expression of ThPOK and FOXP3 after migration to the mucosal epithelium and convert to CD4+ intraepithelial lymphocytes (IEL) $(88,98)$. The expression levels of FOXP3 and ThPOK but not CD4 were significantly lower in carriers compared to non-carriers (Table 6), indicating increased recruitment of FOXP3 + Treg cells to the epithelium during the establishment of FMDV persistent infection.

\section{Apoptosis and Inflammatory Mediators}

IPA pathway analysis indicated cell death and survival could be affected by the differential gene expression. Apoptosis is a well-known cell death mechanism that plays a role in immunity against viral infection. The expression of four pro-apoptotic genes (CASP3, BNIPL, BCL2L14, and BCL2L1) was significantly downregulated by 3.3 - to 8.3 -fold and one anti-apoptotic gene (BNIP2) upregulated by 9.2 -fold in carriers compared to noncarriers (Table 7). CASP3 is a critical caspase in the down-stream of apoptosis pathways that is activated by eternal and external signals such as virus infection, death receptor ligands (TNF,
TRAIL, etc.) and cell-mediated cytotoxicity. TP53 is a tumor suppressor gene and is the top upstream regulator detected in this study. Two TP53-interacting genes, TP53BP1 (TP53 binding protein 1) and TP53RK (TP53 regulating kinase), were expressed at significantly lower levels by $>7$-fold in carriers than in non-carriers (Table 7). TRAF3 and TRAF6 downregulated in carriers (Table 5) could also inhibit viral RNA-induced apoptosis activated by RIG-I-like receptor-induced IRF3 mediated pathway (64). These findings suggest that apoptosis triggered by virus infection might be inhibited in the nasopharyngeal epithelium of FMDV carriers as detected with IPA analysis.

Four downregulated (PTGR1, PTGES, PTGES2, and PTGS1) and one upregulated (PLA2G2A) genes involved in leukotriene B4 (LTB4) and prostaglandin production (103-105) were expressed at higher levels in carriers than in non-carriers (Table 7). The differential expression suggests there is imbalance between LTB4 $(\uparrow)$ and prostaglandin $(\downarrow)$ production. Higher expression of LTB4R, Leukotriene B4 receptor 1 (5.7-fold at $P=$ 0.02 , Table 7), supports increased production of LTB4 in carriers. Interestingly, a probe of bovine immunoglobulin epsilon heavy chain constant region mRNA (NCBI accession \#: AY221098) displayed 3.9-fold increased signal intensity in carriers than 


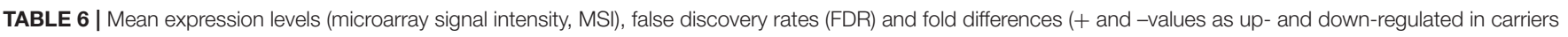
compared to non-carriers, respectively) of genes regulating or expressed on immune cells.

\begin{tabular}{|c|c|c|c|c|c|c|c|}
\hline Group & Gene & MSI & $P$ & FDR & Fold & Functions & References \\
\hline \multirow[t]{2}{*}{ Macrophage } & MFSD6 & 2626 & & 0.03 & -3.9 & $\mathrm{MHC}-\mathrm{I}$ restricted killing by $\mathrm{M} \phi$ & $(80)$ \\
\hline & $\mathrm{MHClb}$ & 1019 & & 0.09 & -7.7 & Non-classical MHC Class I & NCBI \\
\hline \multirow[t]{2}{*}{ NK cell } & NCR3LG1 & 616 & & 0.07 & -4.8 & Membrane NCR3 ligand & (81) \\
\hline & NID1 & 346 & & 0.01 & 12.1 & Extracellular NCR2 ligand & (82) \\
\hline $\begin{array}{l}\text { T cells or intraepithelial } \\
\text { lymphocytes (IEL) }\end{array}$ & CD69 & 121 & & 0.00 & 5.7 & $\begin{array}{l}\text { Inhibit Th17 and CD8+ Teff cells, stimulate Treg cells } \\
\text { and increase tryptophan uptake }\end{array}$ & $(82,83)$ \\
\hline \multirow[t]{10}{*}[-3mm]{} & CD69 & 268 & & 0.00 & 4.9 & & \\
\hline & CD69 & 277 & & 0.00 & 4.9 & & \\
\hline & CD98 & 3005 & 0.20 & 0.55 & -1.6 & Transport of tryptophan & (83) \\
\hline & LAT1 & 7268 & & 0.05 & -2.8 & & \\
\hline & $\mathrm{CD} 27$ & 556 & & 0.00 & -4.4 & CD8+ T cell cytotoxicity & $(42)$ \\
\hline & CD244/2B4 & 450 & & 0.03 & -4.9 & NK and CD8+ T cell cytotoxicity & $(47,48)$ \\
\hline & TNFRSF19 & 1468 & & 0.00 & -9.4 & $\downarrow$ TGF $\beta$ effect on CD8+ cells & $(84,85)$ \\
\hline & IGHD & 587 & & 0.01 & 2.3 & $\operatorname{lgD}$ on $\gamma \delta T$ cells & $(86)$ \\
\hline & CD103 & 3984 & 0.03 & 0.21 & -2.5 & Resident memory T cells & $(87)$ \\
\hline & T-bet & 564 & & 0.05 & 4.5 & $\uparrow$ in non-helped Trm & $(88,89)$ \\
\hline \multirow[t]{8}{*}{ Th17 cell } & RORC & 748 & 0.03 & 0.24 & -5.9 & Th17 transcription factor & NCBI \\
\hline & STAT3 & 17482 & 0.01 & 0.13 & -1.5 & Promote Th17 differentiation & (90) \\
\hline & TIAM1 & 3826 & & 0.00 & -20.8 & Activate IL-17 promoter & $(91)$ \\
\hline & ETS1 & 881 & & 0.01 & 4.7 & Suppress Th17 differentiation & $(92)$ \\
\hline & IL1RL1/ST2 & 55 & 0.02 & 0.18 & 2.2 & $\uparrow$ on stimulated Th17 & (93) \\
\hline & IL22 & 42 & 0.04 & 0.25 & 1.6 & Inhibit Th17 response & (94) \\
\hline & IL33 & 578 & & 0.02 & 14.7 & $\downarrow$ Th17 & (95) \\
\hline & STAT5B & 2118 & & 0.08 & 4.4 & Inhibit Th17 cell differentiation & (90) \\
\hline \multirow[t]{4}{*}{ Tr1 cell } & CD49B & 216 & & 0.05 & 4.0 & Tr1 cell marker & $(96)$ \\
\hline & EBI3/IL27B & 83 & 0.02 & 0.21 & 3.6 & Stimulate $\operatorname{Tr} 1$ differentiation & $(96)$ \\
\hline & MAF & 1729 & 0.01 & 0.13 & 2.1 & Tr1 transcription factor & (96) \\
\hline & PRDM1 & 2302 & & 0.08 & 2.9 & Tr1 cell marker & $(97)$ \\
\hline \multirow[t]{2}{*}{ Treg cell } & FOXP3 & 116 & & 0.07 & -2.1 & Treg transcription factor & $(98)$ \\
\hline & ThPOK & 3191 & & 0.09 & -2.8 & CD4+ transcription factor & (98) \\
\hline
\end{tabular}

in non-carriers $(\mathrm{P}=0.02)$, indicating higher levels of $\operatorname{IgE}$ in carriers and indirectly supporting the increased production of LTB4 based on the role of LTB4 in allergy (102). The LTB4 and prostaglandin imbalance has been reported to play a role in Mycobacterium tuberculosis persistent infection (121).

\section{Transcription Factor Binding Sites}

TATA box sequences were detected in the proximal promoter regions of CXCL15, CXCL16 and CXCL17 but not in chemerin. There is a $\mathrm{CpG}$ island sequence overlapping transcription start sites of chemerin and CXCL16 genes. There was at least one transcription factor binding site (TFBS) for RELA (A transcription factor activated by the canonical NFKB signaling pathway) detected in the proximal promoters of all four of these chemokine genes (Table 7). There were at least two TFBS for IRF3 and three for STAT1::STAT2 in these proximal promoters except for the chemerin promoter. No TFBS for FOS::JUN, IRF3 or STAT1::STAT2 were found in the chemerin proximal promoter, but five NFKB1 (another transcription factor activated by the canonical NFKB signaling pathway) TFBS were detected in the region. Several TFBS for IRF3, NFKB, and STAT1::STAT2 overlap, suggesting that multiple transcription factors can bind to the same sequences to regulate the transcription at these sites. These predicted TFBS suggest that the transcription of these four chemokine genes could be regulated by the interferon, IRF3, MAPK and/or canonical NFKB signaling pathways.

\section{DISCUSSION}

Persistent infection is not unique to FMDV as most, if not all, picornaviruses can persistently infect cells both in-vitro and in-vivo (122). In some virus families, virus-specific factors promoting persistent infection have been described (e.g., in lymphocytic choriomeningitis virus Clone 13) (123), but it has been demonstrated that virus mutations or specific viral genomic characteristics are not the decisive factors in the establishment of persistent FMDV infection in-vitro or in-vivo $(124,125)$. To date, it is not clear which specific mechanisms allow FMDV to persist in some hosts and why available vaccines can protect animals from clinical disease while not preventing or curing subclinical (primary) or persistent infection of the upper respiratory tract. In the current study, we used Ingenuity Pathway Analysis (IPA) to analyze all DEG and found that immune cell trafficking could be significantly impacted by genes differentially 


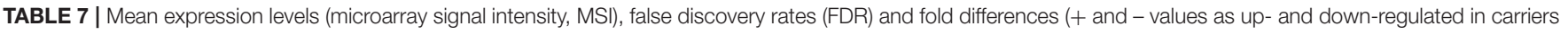
compared to non-carriers, respectively) of genes involved in apoptosis or inflammatory mediator production.

\begin{tabular}{|c|c|c|c|c|c|c|c|}
\hline Group & Gene & MSI & $\boldsymbol{P}$ & FDR & Fold & Functions & References \\
\hline \multirow[t]{7}{*}{ Apoptosis } & CASP3 & 5887 & & 0.07 & -6.9 & Apoptosis activating caspase & (99) \\
\hline & BNIP2 & 708 & & 0.01 & 9.2 & Anti-apoptosis & $\mathrm{NCBI}$ \\
\hline & BNIPL & 30865 & & 0.04 & -3.2 & Pro-apoptosis & $\mathrm{NCBI}$ \\
\hline & BCL2L14 & 832 & & 0.02 & -8.3 & Pro-apoptosis & NCBI \\
\hline & BCL2L1 & 1371 & & 0.02 & -8.2 & Pro-apoptosis & NCBI \\
\hline & TP53BP1 & 1386 & & 0.06 & -7.2 & Pro-apoptosis via NFKB & $(100)$ \\
\hline & TP53RK & 1042 & & 0.07 & -7.3 & Pro-apoptosis via TP53 & $(101)$ \\
\hline \multirow[t]{9}{*}{ Inflammatory mediators } & IGHE & 66 & 0.02 & 0.16 & 3.9 & IgE heavy chain & $\mathrm{NCBI}$ \\
\hline & LTB4R & 170 & 0.02 & 0.18 & 5.7 & Leukotriene B4 receptor 1 & $(102)$ \\
\hline & PTGR1_s & 1554 & & 0.00 & -10.3 & Inactivation of leukotriene B4 & $\mathrm{NCBI}$ \\
\hline & PTGR1_I & 259 & 0.41 & 0.74 & -1.8 & & \\
\hline & PLA2G2A & 161 & & 0.00 & 18.5 & Production of leukotriene B4 and prostaglandins & $(103-105)$ \\
\hline & PLA2G2A & 211 & & 0.00 & 15.7 & & \\
\hline & PTGES & 240 & 0.01 & 0.11 & -2.6 & Prostaglandin E synthesis & \\
\hline & PTGES2 & 715 & & 0.00 & -7.1 & & \\
\hline & PTGS1 & 1499 & 0.04 & 0.27 & -3.3 & Prostaglandin $\mathrm{G} / \mathrm{H}$ synthesis & \\
\hline
\end{tabular}

TABLE 8 | The numbers and locations of predicted transcription factor (TF) binding sites (TFBS) in the proximal promoters (CpG island or 500 bp upstream and 250 bp downstream of TATA box) of chemerin, CXCL15, CXCL16, and CXCL17 genes.

\begin{tabular}{|c|c|c|c|c|}
\hline Gene & Type & TF $^{\mathbf{a}}$ & TFBS & TFBS Location in the proximal promoters ${ }^{b}$ \\
\hline \multirow[t]{2}{*}{ Chemerin } & CpG & NFkB1 & 5 & $\underline{80-92}, 229-241,264-276,296-308,328-340$ \\
\hline & & $\underline{R E L A}$ & 2 & $81-91,523-532$ \\
\hline \multirow[t]{3}{*}{ CXCL15 } & TATA & IRF3 & 6 & $220-240, \underline{277-297}, \underline{305-325}, \underline{664-684}, 690-710, \underline{730-750}$ \\
\hline & & RELA & 1 & $281-290$ \\
\hline & & STAT1::STAT2 & 4 & $\underline{304-318}, 372-386, \underline{665-679}, \underline{731-746}$ \\
\hline \multirow[t]{6}{*}{ CXCL16 } & TATA and CpG & CREB5 & 1 & $\underline{124-135}$ \\
\hline & & FOS::JUN & 1 & $\underline{124-135}$ \\
\hline & & IRF3 & 5 & $409-429, \underline{414-434}, 420-440,426-446, \underline{698-706}$ \\
\hline & & NFKB1 & 1 & $\underline{519-531}$ \\
\hline & & RELA & 2 & $\underline{519-528}, 789-798$ \\
\hline & & STAT1::STST2 & 3 & $\underline{419-433}, 525-539, \underline{693-707}$ \\
\hline \multirow[t]{4}{*}{ CXCL17 } & TATA & FOS::JUN & 1 & $70-82$ \\
\hline & & IRF3 & 2 & $363-383, \underline{381-401}$ \\
\hline & & RELA & 1 & 388-397 \\
\hline & & STAT1::STAT2 & 3 & $364-378$, 388-402, 524-537 \\
\hline
\end{tabular}

anderlines indicate that TFBS are present in all proximal promoters.

${ }^{b}$ Underlines indicate overlapping of TFBS for different transcription factors in the proximal promoter.

expressed between the nasopharyngeal epithelium of FMDV carriers and non-carriers.

It is well-known that immune cell trafficking is controlled by chemokines, and these immune cells express various receptors to respond to chemokine gradients. In the mucosa, epithelial cells express several chemokines to recruit immune cells to control mucosal infections and maintain homeostasis (126). Among five chemokine genes that were downregulated in the nasopharyngeal mucosa of FMDV carriers, chemerin, CXCL15, CXCL16, and CXCL17 have been reported to be expressed by epithelial cells $(32,34,127,128)$. Our results (Figure 2) also show that the expression of these four genes was higher in the micro-dissected epithelium than in whole tissue macerates of samples from the corresponding anatomic sites.

The mucosal immune system is separated into inductive and effector sites based upon anatomical and functional properties (129). Antigen presenting cells (APC) such as dendritic cells bind antigens in effector sites and migrate to mucosa-associated lymphoid tissues (inductive sites) where they present antigen epitopes to $\mathrm{T}$ cells and induce a specific set of chemokine receptors on the $\mathrm{T}$ cells to specifically migrate back to the mucosa (the effector sites). Chemerin recruits plasmacytoid dendritic cells, immature myeloid dendritic cells, macrophages and natural killer cells by binding to three different receptors; ChemR23, GPR1, and CCRL2 (30, 130). Downregulated expression of 




FIGURE 2 | The normalized microarray signal intensity (photons per pixel) of six differentially expressed chemokines in total RNA prepared from micro-dissected pharyngeal epithelia and whole pharyngeal tissues.

chemerin in carriers could reduce recruitment of dendritic cells to the epithelium, which could hinder the induction and reactivation of an adapted immunity. A potentially reduced recruitment of dendritic cells in FMDV carriers was further supported by downregulated expression of four APC-expressed genes (CD276/B7-H3, CLEC9A/DNGR1, VISTA/B7-H5, and VTCN1/B7-H4 (Table 2).

CXCL16 and CXCL17 are ELR- CXCL chemokines. CXCL16 has a strong chemotactic activity for activated CD8 $+\mathrm{T}$ cells, CD4+ T cells, NKT cells and intraepithelial lymphocytes (IEL) but weak or no activity for unstimulated $\mathrm{T}$ cells $(33,35)$. The expression of CXCL16 receptor (CXCR6) on T cells in the lung is correlated with local protective immunity against Mycobacterium tuberculosis (131). Like CXCL16, CXCL17 is chemotactic for antigen-experienced memory CD8 $+\mathrm{T}$ cells such as memory $\mathrm{T}$ effector (Tem) and resident memory (Trm) cells (132). CXCR8 is the receptor of CXCL17. CXCL17 null mice developed fewer CXCR8+ CD8+ Tem and Trm cells and exhibited greater herpes virus replication and susceptibility to latent herpes infection in the mucosa compared to wild-type mice (132). Like chemerin, CXCL17 also recruits antigen presenting cells such as immature dendritic cells $(36,133)$. Significant downregulation of CXCL16 and CXCL17 could reduce recruitment of antigen-experienced T cells to the infected epithelium, which then reduced the killing of infected cells.

In contrast, the recruitment of NK cells into persistently infected epithelium might increase based on upregulated expression of CCL2, CD16, and two KLR receptors (Table 3). NK cells can kill FMDV infected cells and the cytotoxicity can be enhanced by cytokines such as IL-2, IL-15, IL-18, and IFN- $\alpha$ (134). IFNA, IFNL, and IL15 were expressed in significantly higher levels in carriers than in non-carriers; however, downregulated NCR3 ligand (NCR3LG1/B7-H6) and upregulated extracellular NCR2 ligand (NID1), a NK cell cytotoxicity inhibitor (81) could significantly reduce interaction between infected epithelial cells and NK cells and compromise the effectiveness of NK cells in killing of FMDV infected cells. Therefore, the killing of FMDV infected epithelial cells by both antigen-specific cytotoxic T cells and NK cells could be compromised as discussed earlier and later based on upregulated CD69.

Although killing of infected cells reduces virus replication, additional mechanisms such as extracellular traps and phagocytosis by neutrophils or macrophages are needed to limit virus spread and clear infection from the host. All ELR+ chemokines, including CXCL1, CXCL2, CXCL3, CXCL5, CXCL6, and CXCL8, have a chemotactic activity for neutrophils via binding to CXCR2 (27). CXCL6 and CXCL8 can also bind to CXCR1 (135). CXCR1 and CXCR2 are known to be predominately expressed on neutrophils $(27,40)$. Downregulated expression of ELR + chemokines (Table 2), CXCR1 and CXCR2 and other neutrophil-expressed genes in carriers (Table 3) strongly supports reduced recruitment of neutrophils in carriers. Because neutrophils produce CCL23 (136), lower CCL23 expression in carriers also indirectly supports our hypothesis.

CXCL15 is another ELR+ CXCL chemokine reported in mice and has a strong chemotactic activity for neutrophils (32). CXCL15-null mice were more susceptible to Klebsiella pneumoniae infection than wild-type mice (137). We have recently identified a novel bovine CXCL15 in cattle (138). The expression of CXCL15 was significantly downregulated in carriers compared to non-carriers and total expression of all seven bovine ELR+ CXCLs was also 2.4-fold lower in carriers (Table 2). CXCL15 gene appears to be not functional in water buffalo (Bubalus bubalis) due to early stop codon mutation (138). Interestingly, there is limited evidence that Asian buffalo are more susceptible to persistent FMDV infection based on higher percentage of FMDV persistence in buffalo than in cattle in one study (139), which indirectly supports the role of CXCL15 in FMDV persistence. 
It is well-known that neutrophils are the most numerous circulating immune cells and play a critical role in the first line of defense against infections by engulfing and destroying pathogens as well as secreting anti-microbials, cytokines and chemokines to recruit other immune cells $(140,141)$. Neutrophils can also release neutrophil extracellular traps (NET) to immobilize and inactivate viruses (142). NET are extracellular fibril matrices composed of granule proteins and chromatin released by activated neutrophils (143), which has been reported to play a role in eliminating virus infections $(144,145)$.

To understand why the expression of chemerin, CXCL15, CXCL16, and CXCL17 chemokines was downregulated in carriers, we first examined the expression of cytokines. Unexpectedly, all significantly differentially expressed cytokine genes were upregulated in carriers and all are proinflammatory (Table 4). Upregulated expression of the cytokines probably was due to increased recruitment of monocytes into the epithelium of FMDV carriers based on upregulated CCL2, C5AR1, CD16, CD300, CD300LD, MIR155HG, and MMD expression (Tables 2, 3, 5). MMD overexpression has been shown to increase TNF production in a macrophage cell line (62). Co-culture of IL15-stimulated NK cells with blood mononuclear cells induced TNF production in macrophages, which in turn induced CD69 expression on lymphocytes (146). CD69 and IL15 were also significantly upregulated in carriers in the current study (Table 4).

TNF was the most upregulated cytokine in carriers. The expression of another TNF cytokine (TNFSF10 or TRAIL) also known to be able to kill virus-infected cells via death receptor signaling to induce apoptosis (147) was also upregulated in carriers. The expression levels of TNF and TRAIL were higher in the lung (the tissue susceptible to acute FMDV infection but resistant to persistent infection) than in pharyngeal tissues (20). It may be concluded that TNF and TRAIL probably are not very effective in killing FMDV infected cells in carriers because apoptosis induced by these two cytokines could be suppressed by the significantly down-regulated (6.9-fold) expression of a key apoptosis activator, CASP3 (99) and other apoptosisrelated genes listed in Table 7. Interestingly, TP53 (a tumor suppresser gene) was the top regulator detected in this study. TP53BP1 interacts with TP53 and NFKB and can sensitize breast cancer cells to apoptosis induced by TNF treatment (100). TP53RK is a TP53 kinase that can phosphorylate and activate TP53 (101). Therefore, significantly downregulated CASP3, TB53RK and TP53BP1 together with TRAF3 and TRAF6, the signal transducers in RIG-I-induced IRF3 mediated pathway of apoptosis (64), strongly support the suppression of apoptosis induced by death receptor signaling, virus RNA and cellmediated cytotoxicity in carriers.

IL33 was the second most upregulated (14.7-fold) cytokine in FMDV carriers. The receptor of IL33 is constitutively expressed on mast cells, group 2 innate lymphoid cells and Tregs. IL33 plays a key regulatory role in mucosal immunity (95). This cytokine promotes the accumulation and function of myeloid-derived suppressor cells (148) and regulatory Tcells in the intestine (149), induces alternative activation of macrophages (150) and has a potent suppressive effect on innate antiviral immunity (151). Epithelial cells are the major source of IL33 production in the intestine during inflammation (93). Stimulation of IL33 changed the Th17 expression profile in favor of an immunosuppressive phenotype (93). The expression of IL33 in macrophages can be induced by aryl hydrocarbon receptor (AHR) (152). It is well-known that AHR plays a critical role in mucosal immunity (153).

Interestingly, CD69 can increase uptake of L-tryptophan through LAT1-CD98 for converting tryptophan into AHR ligands to activate AHR signaling (83) and CD69 was one of the most consistently upregulated genes in carriers (Table 6). Significantly downregulated CD98/LAT1 in carriers (Table 6) could reduce the effect of upregulated CD69 on AHR ligand production. However, CD69 also has a broad immune suppressive effect via receptor signaling (82). The expression of CD69 and miR-155 (also upregulated in carriers in this study) are coregulated in a positive-feedback loop to promote Treg cell differentiation (154). Increased CD69 expression enhances immunosuppressive function of regulatory T-cells $(155,156)$, suppressed Th17 cell differentiation $(82,118,157)$ and $\mathrm{T}$ cell cytotoxicity (158).

The expression of CD69 on lymphocytes in the gut appears to depend on the microflora because germ-free mice and the ablation of microflora decreased CD69 expression (159, 160). Sustained expression of CD69 on activated T lymphocytes depends on non-canonical NFKB signaling (161). Interestingly, our results indicate that the activation of upregulated IL1s and TNFs in NFKB signaling pathways were routed to the noncanonical pathway due to significantly upregulated $\mathrm{IKK} \alpha$ and downregulated IKK $\beta$ and IKK $\gamma$ (Table 5). The activation of the non-canonical pathway is known to play a role in peripheral immune tolerance and secondary lymphoid tissue development (71). FMDV persistent infection was observed in the follicleassociated epithelia of the nasopharyngeal mucosa $(7,10)$.

Next we examined the differential expression of genes involved in cytokine signaling pathways. The results listed in Table 5 could significantly suppress the expression of downregulated chemokines in carriers. IL17A and IL17F activate $\mathrm{NF} \mathrm{B}$ signaling pathways and play an important role in mucosal immunity via inducing chemokine expression to recruit neutrophils $(162,163)$. It induces neutrophil recruiting ELR+ CXCL chemokines in epithelial cells (164) and increases the stability of CXCL1 and CXCL5 mRNA $(165,166)$. Interestingly, the expression of IL17RA (the IL17A and IL17F receptor) was significantly downregulated in carriers, which could inhibit the response of epithelial cells to IL17 stimulation. Additionally, downregulated $\mathrm{NFkB}$ signaling enhancers and CHUK/IKK $\alpha$ and upregulated signaling inhibiters, IKK $\beta$ and IKK $\gamma$ (Table 5) could play a significant role in the downregulated chemokine expression.

Third, we examined more DEG that could suppress the immune response. DEG listed in Table 6 indicate that the cytotoxicity of macrophages, NK cells and CD8+ cytotoxic T cells and especially the Th17 response could be suppressed in carriers. As stated earlier for IL33 and CD69, there were two more DEG upregulated in carriers (ETS1 and STAT5B) known to suppress Th17 differentiation (90, 92, 119), whereas 
TIAM1 needed for IL17 expression (91) was downregulated by 20 -fold in carriers (Table 6). These results could explain why upregulated Th17-stimulatory cytokines did not result in higher IL17 expression in carriers (Table 4). Therefore, the suppression on the Th17 response could also play a role in FMDV persistent infection.

Finally, we predicted the TFBS in the proximal promoters of the four epithelium-expressed chemokines; chemerin CXCL15, CXCL16, and CXCL17, to infer if inhibition of the signaling pathways could reduce the expression of these four chemokine genes. The results of the promoter analysis indicate that the expression of all four chemokines relies on the activation of canonical NFKB (NFKB1 and RELA) transcription factors, whereas CXCL15, CXCL16, and CXCL17 may also depend on IRF3, interferon and MAPK signaling pathways. CXCL15 expression has been shown to increase under inflammatory conditions such as antigen and LPS stimulation and infection $(32,167)$. IFN $\gamma$ and TNF stimulates CXCL16 and CXCL17 RNA expression in cultured cells $(126,168)$. IFN $\gamma$ and TNF appear to have a synergetic effect on CXCL16 expression, indicating that multiple transcription factors act together to regulate expression of this chemokine. Interestingly, the differential expression of DEG listed in Table 5 could inhibit these signaling pathways especially canonical NFKB signaling pathway, which is known to be activated by IL-17, IL-33, and TNF as stated earlier.

Our previous study using whole pharyngeal tissues showed cytokine and Tr1-expressed genes being differentially expressed between carriers and non-carriers (21). In current study, only two Tr1 marker genes (CD49B and PRDM1) were significantly upregulated in carriers, and one transcription factor (MAF) and one cytokine (IL27B) critical for $\operatorname{Tr} 1$ differentiation (96) were upregulated $(\mathrm{p} \leq 0.02)$ at non-significant levels. The expression

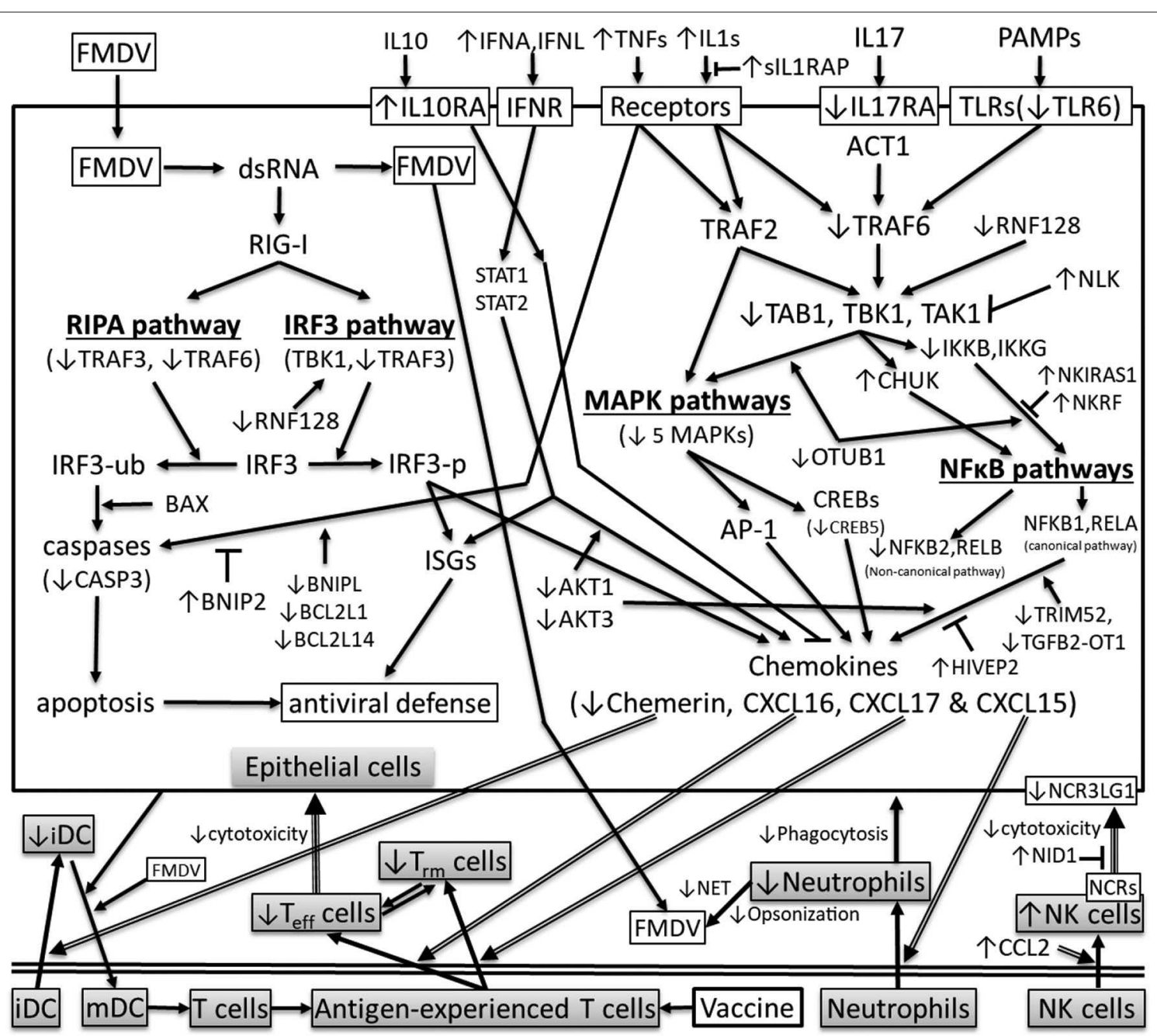

FIGURE 3 | Differentially expressed genes in cytokine signaling pathways that could affect the transcriptions of chemerin, CXCL15, CXCL16, and CXCL17 in the pharyngeal epithelial cells of FMDV carriers ( $\uparrow$ or $\downarrow$ : significantly up- or downregulated in carriers compared to non-carriers, respectively; arrow: stimulation; $\uparrow$ inhibition; iDC and mDC: immature and mature DC; IRF3-ub and IRF3-p: ubiquitinated and phosphorylated IRF3, respectively; ISGs: interferon-stimulated genes; MAPKs: mitogen-activated protein kinases; NCRs: NK cell receptors; NET: neutrophil extracellular traps; RIPA: RIG-I-like receptor-induced IRF3 mediated pathway of apoptosis; $T_{\text {eff }}$ : effector $T$ cells; $T_{\text {rm }}$ : memory $T$ cells; double line arrow: cell recruitment; double line: separation between epithelium and other tissues). 
of IL10, a typical cytokine produced by $\operatorname{Tr} 1$ cells, was not differentially expressed. EBI3, one of an immunosuppressive cytokine IL35 dimer, was upregulated $(p=0.02)$ at a nonsignificant level. The differences could be due different tissue sampling in the study. Most regulatory T cells reside in the lamina propria instead of the epithelia (129).

A higher significant threshold (FDR $\leq 0.05)$ was used in the previous study of this set of microarray data used in current study (22). Most of the DEG listed in current study was not evaluated in the previous study. Immunohistochemistry analysis using anti-CD3D, anti-CD8A and anti- $\gamma \delta$ TCR antibodies showed no differences in the numbers of the detected cell populations between carriers and non-carriers (22). These antibodies could not distinguish between naïve and antigen-experienced effector $\mathrm{T}$ cells. The results generally agree with the results found in current study of no differences in overall $\mathrm{T}$ cell population sizes, though the results of the current study suggest increased naïve $\mathrm{T}$ cell/natural IEL- and decreased effector T cell-recruitment.

In conclusion, the IPA pathway analysis suggests that the detected differential gene expression could affect cell death and survival, immune cell trafficking and hematological system development and function. Four chemokines (chemerin, CXCL15, CXCL16, and CXCL17) recruiting neutrophils, antigenexperienced $\mathrm{T}$ cells and/or dendritic cells were downregulated in FMDV carriers, whereas macrophage and NK cell recruiting CCL2 was upregulated. Other DEG support the differential expression of the chemokines, as shown throughout these analyses. Although all differentially expressed cytokines were upregulated and proinflammatory, the DEG in signaling pathways suggested that the interferon, IRF3, MAPK, and NFKB signaling pathways especially the canonical NFKB pathway could be inhibited in carriers. The TFBS predicted from the proximal promoters indicated that the expression of these downregulated chemokines depends on the activation of these signaling pathways. DEG such as CASP3, CD69, IL17RA, IL33, NCR3LG1, NID1, TP53BP1, TRAF3, and TRAF6 indicated that the Th17 response, NK cell cytotoxicity and apoptosis could be suppressed in carriers. Therefore, based on our results and published gene functions, we hypothesize that (1) under-expression of chemokines that recruit neutrophils, antigen-experienced $\mathrm{T}$ cells

\section{REFERENCES}

1. Arzt J, Pacheco JM, Rodriguez LL. The early pathogenesis of foot-andmouth disease in cattle after aerosol inoculation. Identification of the nasopharynx as the primary site of infection. Vet Pathol. (2010) 47:104863. doi: 10.1177/0300985810372509

2. Stenfeldt C, Eschbaumer M, Pacheco JM, Rekant SI, Rodriguez LL, Arzt J. Pathogenesis of primary foot-and-mouth disease virus infection in the nasopharynx of vaccinated and non-vaccinated cattle. PLOS ONE. (2015) 10:e0143666. doi: 10.1371/journal.pone.0143666

3. Stenfeldt C, Hartwig EJ, Smoliga GR, Palinski R, Silva EB, Bertram MR, et al. Contact challenge of cattle with foot-and-mouth disease virus validates the role of the nasopharyngeal epithelium as the site of primary and persistent infection. mSphere. (2018) 3:e00493-18. doi: 10.1128/mSphere.00493-18

4. Burrows R. Studies on the carrier state of cattle exposed to foot-and-mouth disease virus. J Hyg. (1966) 64:81-90. doi: 10.1017/S0022172400040365 and dendritic cells, (2) blocking NK cell binding to infected cells and (3) suppression of cell-mediated cytotoxicity-, death receptor signaling- and viral RNA-induced apoptosis compromised virus clearance and allowed FMDV to persist as shown in Figure 3. These hypothesized mechanisms indicate that vaccines may not be effective in curing FMDV persistent infection. This study provides novel insights for further investigation.

\section{DATA AVAILABILITY STATEMENT}

The datasets generated for this study can be found in the Michael Eschbaumer, http://www.ncbi.nlm.nih.gov/geo/query/ acc.cgi? acc $=$ GSE 104058 .

\section{ETHICS STATEMENT}

The animal study was reviewed and approved by Plum Island Institutional Animal Care and Use Committee (Protocol numbers 209-12-R, 209-15-R).

\section{AUTHOR CONTRIBUTIONS}

JZ designed the bovine microarray and the microarray experiment, conducted gene annotation, bioinformatic analysis, and wrote the manuscript. JA and CS conceived and executed the primary animal studies and laboratory analysis. CS collected and analyzed the animal samples and performed tissue microdissection. EB performed gene annotation. ME performed microarray analyses and statistical analysis of the data. All authors reviewed and edited in the manuscript.

\section{FUNDING}

The data used in this study is derived from research funded by the U.S. Department of Agriculture, Agricultural Research ServiceCRIS project 1940-32000-061-00D and an interagency agreement with the Science and Technology Directorate of the U.S. Department of Homeland Security under award no. HSHQDC11-X-00131.
5. Burrows R. The persistence of foot-and-mouth disease virus in sheep. J Hyg. (1968) 66:633-40. doi: 10.1017/S0022172400028369

6. Moonen P, Schrijver R. Carriers of foot-and-mouth disease virus: a review. Vet. Q. (2000) 22:193-7. doi: 10.1080/01652176.2000.96 95056

7. Stenfeldt C, Eschbaumer M, Rekant SI, Pacheco JM, Smoliga GR, Hartwig EJ, et al. The foot-and-mouth disease carrier state divergence in cattle. J Virol. (2016) 90:6344-64. doi: 10.1128/JVI.00388-16

8. Bertram MR, Vu LT, Pauszek SJ, Brito BP, Hartwig EJ, Smoliga GR, et al. Lack of transmission of foot-and-mouth disease virus from persistently infected cattle to naïve cattle under field conditions in Vietnam. Front Vet Sci. (2018) 5:174. doi: 10.3389/fvets.2018.00174

9. Zhang ZD, Kitching RP. The localization of persistent foot and mouth disease virus in the epithelial cells of the soft palate and pharynx. J Comp Pathol. (2001) 124:89-94. doi: 10.1053/jcpa.200 0.0431 
10. Pacheco JM, Smoliga GR, O’Donnell V, Brito BP, Stenfeldt C, et al. Persistent foot-and-mouth disease virus infection in the nasopharynx of cattle; tissuespecific distribution and local cytokine expression. PLOS ONE. (2015) 10:e0125698. doi: 10.1371/journal.pone.0125698

11. Arzt J, Belsham GJ, Lohse L, Bøtner A, Stenfeldt C. Transmission of foot-and-mouth disease from persistently infected carrier cattle to naive cattle via transfer of oropharyngeal fluid. mSphere. (2018) 3:18. doi: 10.1128/mSphere.00365-18

12. Zhang Z, Alexandersen S. Quantitative analysis of foot-and-mouth disease virus RNA loads in bovine tissues: implications for the site of viral persistence. J Gen Virol. (2004) 85(Pt 9):2567-75. doi: 10.1099/vir.0.80011-0

13. Zhang Z, Murphy C, Quan M, Knight J, Alexandersen S. Extent of reduction of foot-and-mouth disease virus RNA load in oesophageal-pharyngeal fluid after peak levels may be a critical determinant of virus persistence in infected cattle. J Gen Virol. (2004)85(Pt 2):415-21. doi: 10.1099/vir.0.19538-0

14. Salt JS, Mulcahy G, Kitching RP. Isotype-specific antibody responses to footand-mouth disease virus in sera and secretions of "carrier' and "non-carrier" cattle. Epidemiol Infect. (1996) 117:349-60. doi: 10.1017/S0950268800001539

15. Maddur MS, Gajendragad MR, Kishore S, Chockalingam AK, Suryanarayana VV, Gopalakrishna S. Enhanced mucosal immune response in cattle persistently infected with foot-and-mouth disease virus. Vet Immunol Immunopathol. (2008) 125:337-43. doi: 10.1016/j.vetimm.2008.05.031

16. Maddur MS, Kishore S, Chockalingam AK, Gopalakrishna S, Singh N, Suryanarayana VV, et al. The relationship between cellular immune response to foot-and-mouth disease virus Asia 1 and viral persistence in Indian cattle (Bos indicus). Res Vet Sci. (2010) 89:36-40. doi: 10.1016/j.rvsc.2010.01.018

17. Oh Y, Fleming L, Statham B, Hamblin P, Barnett P, Paton DJ, et al. Interferon$\gamma$ induced by in vitro re-stimulation of CD4+ T-cells correlates with in vivo FMD vaccine induced protection of cattle against disease and persistent infection. PLoS ONE. (2012) 7:e44365. doi: 10.1371/journal.pone.0044365

18. Zhang $\mathrm{Z}$, Doel C, Bashiruddin JB. Interleukin-10 production at the early stage of infection with foot-and-mouth disease virus related to the likelihood of persistent infection in cattle. Vet Res. (2015) 46:132. doi: 10.1186/s13567-015-0276-y

19. Stenfeldt C, Arzt J, Smoliga G, LaRocco M, Gutkoska J, Lawrence P. Proof-of-concept study: profile of circulating microRNAs in Bovine serum harvested during acute and persistent FMDV infection. Virol J. (2017) 14:71. doi: 10.1186/s12985-017-0743-3

20. Zhu JJ, Arzt J, Puckette MC, Smoliga GR, Pacheco JM, et al. Mechanisms of foot-and-mouth disease virus tropism inferred from differential tissue gene expression. PLoS ONE. (2013) 8:e64119. doi: 10.1371/journal.pone.0064119

21. Eschbaumer M, Stenfeldt C, Smoliga GR, Pacheco JM, Rodriguez LL, et al. Transcriptomic analysis of persistent infection with footand-mouth disease virus in cattle suggests impairment of apoptosis and cell-mediated immunity in the nasopharynx. PLOS ONE. (2016) 11:e0162750. doi: 10.1371/journal.pone.0162750

22. Stenfeldt C, Eschbaumer M, Smoliga GR, Rodriguez LL, Zhu JJ, et al. Clearance of a persistent picornavirus infection is associated with enhanced pro-apoptotic and cellular immune responses. Sci Rep. (2017) 7:1780014. doi: 10.1038/s41598-017-18112-4

23. Ritchie ME, Phipson B, Wu D, Hu Y, Law CW, Shi W, el al. limma powers differential expression analyses for RNA-sequencing and microarray studies. Nucleic Acids Research, (2015) 43:e47. doi: 10.1093/nar/ gkv007

24. Reese MG. Application of a time-delay neural network to promoter annotation in the Drosophila melanogaster genome. Comput Chem. (2001) 26:51-6. doi: 10.1016/S0097-8485(01)00099-7

25. Schug J. Using TESS to predict transcription factor binding sites in DNA sequence. Curr Protoc Bioinformatics. (2008) Chapter. 2: Unit 2.6. doi: 10.1002/0471250953.bi0206s00

26. Shi C, Pamer EG. Monocyte recruitment during infection and inflammation. Nat Rev Immunol. (2011) 11:762-74. doi: 10.1038/nri3070

27. Griffith JW, Sokol CL, Luster AD. Chemokines and chemokine receptors: positioning cells for host defense and immunity. Annu Rev Immunol. (2014) 32:659-702. doi: 10.1146/annurev-immunol-032713-120145

28. Morrison BE, Park SJ, Mooney JM, Mehrad B. Chemokine-mediated recruitment of NK cells is a critical host defense mechanism in invasive aspergillosis. J Clin Invest. (2003) 112:1862-70. doi: 10.1172/JCI18125
29. Patel VP, Kreider BL, Li Y, Li H, Leung K, Salcedo T, et al. Molecular and functional characterization of two novel human C-C chemokines as inhibitors of two distinct classes of myeloid progenitors. J Exp Med. (1997) 185:1163-72. doi: 10.1084/jem.185.7.1163

30. Wittamer V, Franssen JD, Vulcano M, Mirjolet JF, Le Poul E, Migeotte I, et al. Specific recruitment of antigen-presenting cells by chemerin, a novel processed ligand from human inflammatory fluids. J Exp Med. (2003) 198:977-85. doi: 10.1084/jem.20030382

31. Parolini S, Santoro A, Marcenaro E, Luini W, Massardi L, Facchetti $\mathrm{F}$, et al. The role of chemerin in the colocalization of $\mathrm{NK}$ and dendritic cell subsets into inflamed tissues. Blood. (2007) 109:362532. doi: 10.1182/blood-2006-08-038844

32. Rossi DL, Hurst SD, Xu Y, Wang W, Menon S, et al. Lungkine, a novel CXC chemokine, specifically expressed by lung bronchoepithelial cells. J Immunol. (1999) 162:5490-7.

33. Matloubian M, David A, Engel S, Ryan JE, Cyster JG. A transmembrane CXC chemokine is a ligand for HIV-coreceptor Bonzo. Nat Immunol. (2000) 1:298-304. doi: 10.1038/79738

34. Day C, Patel R, Guillen C, Wardlaw AJ. The chemokine CXCL16 is highly and constitutively expressed by human bronchial epithelial cells. Exp Lung Res. (2009) 35:272-83. doi: 10.1080/01902140802635517

35. Shimaoka T, Seino K, Kume N, Minami M, Nishime C, Suematsu $\mathrm{M}$, et al. Critical role for CXC chemokine ligand 16 (SR-PSOX) in Th1 response mediated by NKT cells. J Immunol. (2007) 179:81729. doi: 10.4049/jimmunol.179.12.8172

36. Maravillas-Montero JL, Burkhardt AM, Hevezi PA, Carnevale CD, Smit MJ, Zlotnik A. Cutting edge: GPR35/CXCR8 is the receptor of the mucosal chemokine CXCL17. J Immunol. (2015) 194:29-33. doi: 10.4049/jimmunol.1401704

37. Klos A, Wende E, Wareham KJ, Monk PN. Complement peptide C5a, C4a, C3a receptors. International Union of Basic Clinical Pharmacology. [corrected]. LXXXVII. Pharmacol Rev. (2013) 65:500-43. doi: 10.1124/pr.111.005223

38. Lischke T, Heesch K, Schumacher V, Schneider M, Haag F, KochNolte F, et al. CD38 controls the innate immune response against Listeria monocytogenes. Infect Immun. (2013) 81:4091-9. doi: 10.1128/IAI.00 340-13

39. Estrada-Figueroa LA, Ramírez-Jiménez Y, Osorio-Trujillo C, Shibayama M, Navarro-García F, García-Tovar C, et al. Absence of CD38 delays arrival of neutrophils to the liver and innate immune response development during hepatic amoebiasis by Entamoeba histolytica. Parasite Immunol. (2011) 33:661-8. doi: 10.1111/j.1365-3024.2011.01 333.x

40. Rajarathnam K, Schnoor M, Richardson RM, Rajagopal S. How do chemokines navigate neutrophils to the target site: dissecting the structural mechanisms and signaling pathways. Cell Signal. (2019) 54:6980. doi: 10.1016/j.cellsig.2018.11.004

41. Chan EC, Ren C, Xie Z, Jude J, Barker T, Koziol-White CA, et al. Regulator of $\mathrm{G}$ protein signaling 5 restricts neutrophil chemotaxis and trafficking. J Biol Chem. (2018) 293:12690-702. doi: 10.1074/jbc.RA118.0 02404

42. Grant EJ, Nüssing S, Sant S, Clemens EB, Kedzierska K. The role of CD27 in anti-viral T-cell immunity. Curr Opin Virol. (2017) 22:7788. doi: 10.1016/j.coviro.2016.12.001

43. Beura LK, Masopust D. SnapShot: resident memory T cells. Cell. (2014) 157:1488. doi: 10.1016/j.cell.2014.05.026

44. Thompson LF, Ruedi JM, Low MG, Clement LT. Distribution of ecto5'-nucleotidase on subsets of human $\mathrm{T}$ and $\mathrm{B}$ lymphocytes as detected by indirect immunofluorescence using goat antibodies. J Immunol. (1987) 139:4042-8.

45. Cekic C, Linden J. Adenosine A2A receptors intrinsically regulate $\mathrm{CD} 8+\mathrm{T}$ cells in the tumor microenvironment. Cancer Res. (2014) 74:7239-49. doi: 10.1158/0008-5472.CAN-1 3-3581

46. Tóth I, Le AQ, Hartjen P, Thomssen A, Matzat V, Lehmann C, et al. Decreased frequency of CD73+CD8 $+\mathrm{T}$ cells of HIV-infected patients correlates with immune activation and $\mathrm{T}$ cell exhaustion. J Leukoc Biol. (2013) 94:551-61. doi: 10.1189/jlb.0113018 
47. Lee KM, Bhawan S, Majima T, Wei H, Nishimura MI, Yagita H, et al. Cutting edge: the NK cell receptor 2B4 augments antigen-specific T cell cytotoxicity through CD48 ligation on neighboring $\mathrm{T}$ cells. J Immunol. (2003) 170:4881-5. doi: 10.4049/jimmunol.170.10.4881

48. Kis-Toth K, Comte D, Karampetsou MP, Kyttaris VC, Kannan L, Terhorst $\mathrm{C}$, et al. Selective loss of signaling lymphocytic activation molecule family member 4-positive CD8+ T cells contributes to the decreased cytotoxic cell activity in systemic lupus erythematosus. Arthritis Rheumatol. (2016) 68:164-73. doi: 10.1002/art.39410

49. Shen S, Chuck MI, Zhu M, Fuller DM, Yang CW, Zhang W. The importance of LAT in the activation, homeostasis, and regulatory function of T cells. $J$ Biol Chem. (2010) 285:35393-405. doi: 10.1074/jbc.M110.145052

50. Bartelt RR, Houtman JC. The adaptor protein LAT serves as an integration node for signaling pathways that drive T cell activation. Wiley Interdisc Rev Syst Biol Med. (2013) 5:101-10. doi: 10.1002/wsbm.1194

51. Nayar R, Enos M, Prince A, Shin H, Hemmers S, Jiang JK, et al. TCR signaling via Tec kinase ITK and interferon regulatory factor 4 (IRF4) regulates CD8+ T-cell differentiation. Proc Natl Acad Sci USA. (2012) 109:E27942802. doi: 10.1073/pnas. 1205742109

52. Michie CA, McLean A, Alcock C, Beverley PC. Lifespan of human lymphocyte subsets defined by CD45 isoforms. Nature. (1992) 360:2645. doi: 10.1038/360264a0

53. Sallusto F, Lenig D, Förster R, Lipp M, Lanzavecchia A. Two subsets of memory $\mathrm{T}$ lymphocytes with distinct homing potentials and effector functions. Nature. (1999) 401:708-12. doi: 10.1038/44385

54. Mandelboim O, Malik P, Davis DM, Jo CH, Boyson JE, Strominger JL. Human CD16 as a lysis receptor mediating direct natural killer cell cytotoxicity. Proc Natl Acad Sci USA. (1999) 96:5640-4. doi: 10.1073/pnas.96.10.5640

55. Cheroutre H, Lambolez F, Mucida D. The light and dark sides of intestinal intraepithelial lymphocytes. Nat Rev Immunol. (2011) 11:44556. doi: 10.1038/nri3007

56. Storset AK, Slettedal IO, Williams JL, Law A, Dissen E. Natural killer cell receptors in cattle: a bovine killer cell immunoglobulin-like receptor multigene family contains members with divergent signaling motifs. Eur J Immunol. (2003) 33:980-90. doi: 10.1002/eji.200323710

57. Iborra S, Martínez-López M, Khouili SC, Enamorado M, Cueto FJ, Conde-Garrosa R, et al. Optimal generation of tissue-resident but not circulating memory $\mathrm{T}$ cells during viral infection requires cross-priming by DNGR-1+ dendritic cells. Immunity. (2016) 45:847-60. doi: 10.1016/j.immuni.2016.08.019

58. Chapoval AI, Ni J, Lau JS, Wilcox RA, Flies DB, Liu D, et al. B7-H3: a costimulatory molecule for $\mathrm{T}$ cell activation and IFN-gamma production. Nat Immunol. (2001) 2:269-74. doi: 10.1038/85339

59. Wang L, Rubinstein R, Lines JL, Wasiuk A, Ahonen C, Guo Y, et al. VISTA, a novel mouse Ig super family ligand that negatively regulates T cell responses. J Exp Med. (2011) 208:577-92. doi: 10.1084/jem.201 00619

60. Prasad DV, Richards S, Mai XM, Dong C. B7S1, a novel B7 family member that negatively regulates T cell activation. Immunity. (2003) 18:86373. doi: 10.1016/S1074-7613(03)00147-X

61. Clark GJ, Ju X, Tate C, Hart DN. The CD300 family of molecules are evolutionarily significant regulators of leukocyte functions. Trends Immunol. (2009) 30:209-17. doi: 10.1016/j.it.2009. 02.003

62. Liu Q, Zheng J, Yin DD, Xiang J, He F, Wang YC, et al. Monocyte to macrophage differentiation-associated (MMD) positively regulates ERK and Akt activation and TNF- $\alpha$ and NO production in macrophages. Mol Biol Rep. (2012) 39:5643-50. doi: 10.1007/s11033-011-1370-5

63. Luthra P, Sun D, Wolfgang M, He B. AKT1-dependent activation of NFkappaB by the L protein of parainfluenza virus 5. J Virol. (2008) 82:1088795. doi: 10.1128/JVI.00806-08

64. Chattopadhyay S, Sen GC. RIG-I-like receptor-induced IRF3 mediated pathway of apoptosis (RIPA): a new antiviral pathway. Protein Cell. (2017) 8:165-8. doi: 10.1007/s13238-016-0334-x

65. Shih VF, Tsui R, Caldwell A, Hoffmann A. A single NFкB system for both canonical and non-canonical signaling. Cell Res. (2011) 21:86102. doi: $10.1038 / \mathrm{cr} .2010 .161$
66. Dong C, Davis RJ, Flavell RA. MAP kinases in the immune response. Annu Rev Immunol. (2002) 20:5572. doi: 10.1146/annurev.immunol.20.091301.131133

67. van Delft MA, Huitema LF, Tas SW. The contribution of NF-кB signalling to immune regulation and tolerance. Eur J Clin Invest. (2015) 45:52939. doi: $10.1111 /$ eci. 12430

68. Goncharov T, Niessen K, de Almagro MC, Izrael-Tomasevic A, Fedorova AV, Varfolomeev E, et al. OTUB1 modulates c-IAP1 stability to regulate signaling pathways. EMBO J. (2013) 32:1103-14. doi: 10.1038/emboj.2013.62

69. Song G, Liu B, Li Z, Wu H, Wang P, Zhao K, et al. E3 ubiquitin ligase RNF128 promotes innate antiviral immunity through K63-linked ubiquitination of TBK1. Nat Immunol. (2016) 17:1342-51. doi: 10.1038/ni.3588 s

70. Huang S, Lu W, Ge D, Meng N, Li Y, Su L, et al. A new microRNA signal pathway regulated by long noncoding RNA TGFB2-OT1 in autophagy and inflammation of vascular endothelial cells. Autophagy. (2015) 11:217283. doi: 10.1080/15548627.2015.1106663

71. Fan W, Liu T, Li X, Zhou Y, Wu M, Cui X, et al. TRIM52: A nuclear TRIM protein that positively regulates the nuclear factor-kappa B signaling pathway. Mol Immunol. (2017) 82:114-22. doi: 10.1016/j.molimm.2017.01.003

72. Kimura MY, Hosokawa H, Yamashita M, Hasegawa A, Iwamura C, Watarai $\mathrm{H}$, et al. Regulation of T helper type 2 cell differentiation by murine Schnurri2. J Exp Med. (2005) 201:397-408. doi: 10.1084/jem.20040733

73. Chen Y, Vallee S, Wu J, Vu D, Sondek J, Ghosh G. Inhibition of NF-kappaB activity by IkappaBbeta in association with kappaB-Ras. Mol Cell Biol. (2004) 24:3048-3056. doi: 10.1128/MCB.24.7.3048-3056.2004

74. Yasuda J, Yokoo H, Yamada T, Kitabayashi I, Sekiya T, Ichikawa H. Nemo-like kinase suppresses a wide range of transcription factors, including nuclear factor-kappaB. Cancer Sci. (2004) 95:52-7. doi: 10.1111/j.1349-7006.2004.tb03170.x

75. Nourbakhsh $M$, Hauser H. Constitutive silencing of IFN- $\beta$ promoter is

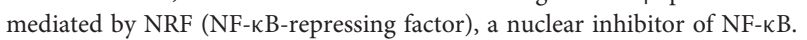
EMBO J. (1999) 18:6415-25. doi: 10.1093/emboj/18.22.6415

76. Gracias DT, Stelekati E, Hope JL, Boesteanu AC, Doering TA, Norton J, et al. The microRNA miR-155 controls CD8(+) T cell responses by regulating interferon signaling. Nat Immunol. (2013) 14:593-602. doi: 10.1038/ni.2576

77. Du H, Cui S, Li Y, Yang G, Wang P, Fikrig E, et al. MiR-221 negatively regulates innate anti-viral response. PLoS ONE. (2018) 13:e0200385. doi: 10.1371/journal.pone.0200385

78. Seeley JJ, Baker RG, Mohamed G, Bruns T, Hayden MS, Deshmukh $\mathrm{SD}$, et al. Induction of innate immune memory via microRNA targeting of chromatin remodeling factors. Nature. (2018) 559:114-9. doi: 10.1038/s41586-018-0253-5

79. Wang H, Liang L, Dong Q, Huan L, He J, Li B, et al. Long noncoding RNA miR503HG, a prognostic indicator, inhibits tumor metastasis by regulating the HNRNPA2B1/NF-кB pathway in hepatocellular carcinoma. Theranostics. (2018) 8:2814-29. doi: 10.7150/thno.23012

80. Kellner C, Maurer T, Hallack D, Repp R, van de Winkel JG, Parren PW, et al. Mimicking an induced self phenotype by coating lymphomas with the NKp30 ligand B7-H6 promotes NK cell cytotoxicity. J Immunol. (2012) 189:5037-46. doi: 10.4049/jimmunol.1201321

81. Gaggero S, Bruschi M, Petretto A, Parodi M, Del Zotto G, Lavarello C, et al. Nidogen-1 is a novel extracellular ligand for the NKp44 activating receptor. Oncoimmunology. (2018) 7:e1470730. doi: 10.1080/2162402X.2018.1470730

82. Radulovic K, Niess JH. CD69 is the crucial regulator of intestinal inflammation: a new target molecule for IBD treatment? J Immunol Res. (2015) 2015:497056. doi: 10.1155/2015/497056

83. Cibrian D, Saiz ML, de la Fuente H, Sánchez-Díaz R, Moreno-Gonzalo O, Jorge I, et al. CD69 controls the uptake of L-tryptophan through LAT1-CD98 and AhR-dependent secretion of IL-22 in psoriasis. Nat Immunol. (2016) 17:985-96. doi: 10.1038/ni.3504

84. Deng C, Lin YX, Qi XK, He GP, Zhang Y, Zhang HJ, et al. TNFRSF19 Inhibits TGF $\beta$ signaling through interaction with TGF $\beta$ receptor type I to promote tumorigenesis. Cancer Res. (2018) 78:346983. doi: 10.1158/0008-5472.CAN-17-3205

85. Sanjabi S, Oh SA, Li MO. Regulation of the Immune Response by TGF- $\beta$ : From Conception to Autoimmunity and Infection. Cold Spring Harb Perspect Biol. (2017) 9:a022236: doi: 10.1101/cshperspect.a022236 
86. Peters C, Kabelitz D, Wesch D. Regulatory functions of $\gamma \delta$ T cells. Cell Mol Life Sci. (2018) 75:2125-35. doi: 10.1007/s00018-018-2788-x

87. Laidlaw BJ, Zhang N, Marshall HD, Staron MM, Guan T, Hu Y, et al. $\mathrm{CD} 4+\mathrm{T}$ cell help guides formation of CD103+ lung-resident memory CD8+ T cells during influenza viral infection. Immunity. (2014) 41:63345. doi: 10.1016/j.immuni.2014.09.007

88. Reis BS, Rogoz A, Costa-Pinto FA, Taniuchi I, Mucida D. Mutual expression of the transcription factors Runx3 and ThPOK regulates intestinal CD4(+) T cell immunity. Nat Immunol. (2013) 14:271-80. doi: 10.1038/ni.2518

89. Klose CS, Blatz K, d'Hargues Y, Hernandez PP, Kofoed-Nielsen M. Ripka JF, et al. The transcription factor T-bet is induced by IL-15 and thymic agonist selection and controls CD8aa+ intraepithelial lymphocyte development. Immunity. (2014) 41:230-43. doi: 10.1016/j.immuni.2014.06.018

90. Zheng Y, Wang Z, Deng L, Zhang G, Yuan X, Huang L, et al. Modulation of STAT3 and STAT5 activity rectifies the imbalance of Th17 and Treg cells in patients with acute coronary syndrome. Clin Immunol. (2015) 157:6577. doi: 10.1016/j.clim.2014.12.012

91. Kurdi AT, Bassil R, Olah M, Wu C, Xiao S, Taga M, et al. Tiam1/Rac1 complex controls Il17a transcription and autoimmunity. Nat Commun. (2016) 7:13048. doi: 10.1038/ncomms13048

92. Moisan J, Grenningloh R, Bettelli E, Oukka M, Ho IC. Ets-1 is a negative regulator of Th17 differentiation. J Exp Med. (2007) 204:282535. doi: 10.1084/jem.20070994

93. Pascual-Reguant A, Bayat Sarmadi J, Baumann C, Noster R, Cirera-Salinas D, Curato C, et al. TH17 cells express ST2 and are controlled by the alarmin IL-33 in the small intestine. Mucosal Immunol. (2017) 10:143142. doi: $10.1038 / \mathrm{mi} .2017 .5$

94. Vivier E, Spits H, Cupedo T. Interleukin-22-producing innate immune cells: new players in mucosal immunity and tissue repair? Nat Rev Immunol. (2009) 9:229-34. doi: 10.1038/nri2522

95. Hodzic Z, Schill EM, Bolock AM, Good M. IL-33 and the intestine: the good, the bad, the inflammatory. Cytokine. (2017) 100:1-10. doi: 10.1016/j.cyto.2017.06.017

96. Zeng $\mathrm{H}$, Zhang $\mathrm{R}$, Jin $\mathrm{B}$, Chen $\mathrm{L}$. Type 1 regulatory $\mathrm{T}$ cells: a new mechanism of peripheral immune tolerance. Cell Mol Immunol. (2015) 12:566-71. doi: $10.1038 / \mathrm{cmi} .2015 .44$

97. Roncarolo MG, Gregori S, Bacchetta R, Battaglia M, Gagliani N. The biology of $\mathrm{T}$ regulatory Type 1 cells and their therapeutic application in immune-mediated diseases. Immunity. (2018) 49:1004-19. doi: 10.1016/j.immuni.2018.12.001

98. Sujino T, London M, Hoytema van Konijnenburg DP, Rendon T, Buch T, Silva HM, et al. Tissue adaptation of regulatory and intraepithelial CD4? T cells controls gut inflammation. Science. (2016) 2016:352:15816. doi: 10.1126/science.aaf3892

99. Porter AG, Jänicke RU. Emerging roles of caspase-3 in apoptosis. Cell Death Differ. (1999) 6:99-104. doi: 10.1038/sj.cdd.4400476

100. Wen Y, Yan DH, Spohn B, Deng J, Lin SY, Hung MC. Tumor suppression and sensitization to tumor necrosis factor alpha-induced apoptosis by an interferon-inducible protein, p202, in breast cancer cells. Cancer Res. (2000) 60:42-6.

101. Facchin S, Ruzzene M, Peggion C, Sartori G, Carignani G, Marin O, et al. Phosphorylation and activation of the atypical kinase p53-related protein kinase (PRPK) by Akt/PKB. Cell Mol Life Sci. (2007) 64:26809. doi: 10.1007/s00018-007-7179-7

102. Liu M, Yokomizo T. The role of leukotrienes in allergic diseases. Allergol Int. (2015) 64:17-26. doi: 10.1016/j.alit.2014.09.001

103. White M. Mediators of inflammation and the inflammatory process. J Allergy Clin Immunol. (1999) 103(3 Pt 2):S37881. doi: 10.1016/S0091-6749(99)70215-0

104. Salmon JA, Higgs GA. Prostaglandins and leukotrienes as inflammatory mediators. Br Med Bull. (1987) 43:28596. doi: 10.1093/oxfordjournals.bmb.a072183

105. Tobin DM, and Ramakrishnan L. TB: the Yin and Yang of lipid mediators. Curr Opin Pharmacol. (2013) 13:641-5. doi: 10.1016/j.coph.2013.06.007

106. Rehli M, Krause SW, Schwarzfischer L, Kreutz M, Andreesen R. Molecular cloning of a novel macrophage maturation-associated transcript encoding a protein with several potential transmembrane domains. Biochem Biophys Res Commun. (1995) 217:661-7. doi: 10.1006/bbrc.1995.2825
107. Saha P, Geissmann F. Toward a functional characterization of blood monocytes. Immunol Cell Biol. (2011) 89:2-4. doi: 10.1038/icb.2010.130

108. Ewen CL, Kane KP, Bleackley RC. A quarter century of granzymes. Cell Death Diff. (2012) 19:28-35. doi: 10.1038/cdd.2011.153

109. Goettel JA, Gandhi R, Kenison JE, Yeste A, Murugaiyan G, Sambanthamoorthy $\mathrm{S}$, et al. AHR activation is protective against colitis driven by $\mathrm{T}$ cells in humanized mice. Cell Rep. (2016) 17:1318-29. doi: 10.1016/j.celrep.2016.09.082

110. Guo RF, Ward PA. Role of C5a in inflammatory responses. Annu Rev Immunol. (2005) 23:82152. doi: 10.1146/annurev.immunol.23.021704.115835

111. Jensen LE. Interleukin-36 cytokines may overcome microbial immune evasion strategies that inhibit interleukin-1 family signaling. Sci Signal. (2017) 10:aan3589. doi: 10.1126/scisignal.aan3589

112. Moore KW, de Waal Malefyt R, Coffman RL, O'Garra A. Interleukin10 and the interleukin-10 receptor. Annu Rev Immunol. (2001) 19:683765. doi: 10.1146/annurev.immunol.19.1.683

113. Floss DM, Schröder J, Franke M, Scheller J. Insights into IL-23 biology: from structure to function. Cytokine Growth Factor Rev. (2015) 26:56978. doi: 10.1016/j.cytogfr.2015.07.005

114. Ezell SA, Tsichlis PN. Akt1, EMSY. BRCA2 and type I IFN signaling: a novel arm of the IFN response. Transcription. (2012) 3:305-9. doi: 10.4161/trns.21904

115. Rothchild AC, Sissons JR, Shafiani S, Plaisier C, Min D, Mai D, et al. MiR-155regulated molecular network orchestrates cell fate in the innate and adaptive immune response to Mycobacterium tuberculosis. Proc Natl Acad Sci USA. (2016) 113:E6172-81. doi: 10.1073/pnas.1608255113

116. Huang J, Jiao J, Xu W, Zhao H, Zhang C, Shi Y, et al. MiR-155 is upregulated in patients with active tuberculosis and inhibits apoptosis of monocytes by targeting FOXO3. Mol Med Rep. (2015) 12:71028. doi: $10.3892 / \mathrm{mmr} .2015 .4250$

117. Yoshida R. MHC class I recognition by monocyte/macrophage-specific receptors. Adv Immunol. (2014) 124:20747. doi: 10.1016/B978-0-12-800147-9.00007-8

118. Martin P, Gomez M, Lamana A, Cruz-Adalia A, RamirezHuesca M, Ursa MA, et al. CD69 association with Jak3/Stat5 proteins regulates Th17 cell differentiation. Mol Cell Biol. (2010) 30:4877-89. doi: 10.1128/MCB.00456-10

119. Qiu J, Guo X, Chen ZM, He L, Sonnenberg GF, Artis D, et al. Group 3 innate lymphoid cells inhibit T-cell-mediated intestinal inflammation through aryl hydrocarbon receptor signaling and regulation of microflora. Immunity. (2013) 39:386-99. doi: 10.1016/j.immuni.2013.08.002

120. Apetoh L, Quintana FJ, Pot C, Joller N, Xiao S, Kumar D, et al. The aryl hydrocarbon receptor interacts with c-Maf to promote the differentiation of type 1 regulatory T cells induced by IL-27. Nat Immunol. (2010) 11:85461. doi: $10.1038 /$ ni.1912

121. Pedruzzi G, Das PN, Rao KV, Chatterjee S. Understanding PGE2, LXA4 and LTB4 balance during Mycobacterium tuberculosis infection through mathematical model. J Theor Biol. (2016) 389:159-70. doi: 10.1016/j.jtbi.2015.10.025

122. Colbere-Garapin F, Pelletier I, Ouxilou L. Persistent infections by picornaviruses. In: Semler BL, Wimmer E, editors. Molecular Biology of Picornaviruses. Washington, DC: ASM Press (2002). p. 437-48. doi: 10.1128/9781555817916.ch35

123. Sullivan BM, Emonet SF, Welch MJ, Lee AM, Campbell KP, de la Torre JC, et al. Point mutation in the glycoprotein of lymphocytic choriomeningitis virus is necessary for receptor binding, dendritic cell Infection, long-term persistence. Proc Natl Acad Sci USA. (2011) 108:296974. doi: 10.1073/pnas.1019304108

124. Han L, Xin X, Wang H, Li J, Hao Y, Wang M, et al. Cellular response to persistent foot-and-mouth disease virus infection is linked to specific types of alterations in the host cell transcriptome. Sci Rep. (2018) 8:5074. doi: 10.1038/s41598-018-23478-0

125. Arzt J, Fish I, Pauszek SJ, Johnson SL, Chain PS, Rai DK, et al. The evolution of a super-swarm of foot-and-mouth disease virus in cattle. PLOS ONE. (2019) 14:e0210847. doi: 10.1371/journal.pone.0210847

126. Hernández-Ruiz M, Zlotnik A. Mucosal chemokines. J Interferon Cytokine Res. (2017) 37:62-70. doi: 10.1089/jir.2016.0076 
127. Luangsay S, Wittamer V, Bondue B, De Henau O, Rouger L, Brait M, et al. Mouse ChemR23 is expressed in dendritic cell subsets and macrophages and mediates an anti-inflammatory activity of chemerin in a lung disease model. J Immunol. (2009) 183:6489-99. doi: 10.4049/jimmunol.0901037

128. Burkhardt AM, Tai KP, Flores-Guiterrez JP, Vilches-Cisneros N, Kamdar K, Barbosa-Quintana O, et al. CXCL17 is a mucosal chemokine elevated in idiopathic pulmonary fibrosis that exhibits broad antimicrobial activity. $J$ Immunol. (2012) 188:6399-406. doi: 10.4049/jimmunol.1102903

129. McGhee JR, Fujihashi K. Inside the mucosal immune system. PLoS Biol. (2012) 10:e1001397. doi: 10.1371/journal.pbio.1001397

130. Bondue B, Wittamer V, Parmentier M. Chemerin and its receptors in leukocyte trafficking, inflammation and metabolism. Cytokine Growth Factor Rev. (2011) 22:331-8. doi: 10.1016/j.cytogfr.2011.11.004

131. Lee LN, Ronan EO, de Lara C, Franken KL, Ottenhoff TH, Tchilian EZ, et al. CXCR6 is a marker for protective antigen-specific cells in the lungs after intranasal immunization against Mycobacterium tuberculosis. Infect Immun. (2011) 79:3328-37. doi: 10.1128/IAI.01133-10

132. Srivastava R, Hernández-Ruiz A, Khan AA, Fouladi MA, Kim GJ. Ly VT, et al. CXCL17 chemokine-dependent mobilization of CXCR8+CD8+ effector memory and tissue-resident memory $\mathrm{T}$ cells in the vaginal mucosa is associated with protection against genital herpes. J Immunol. (2008) 200:2915-26. doi: 10.4049/jimmunol.1701474

133. Pisabarro MT, Leung B, Kwong M, Corpuz R, Frantz GD, Chiang N, et al. Cutting edge: novel human dendritic cell- and monocyte-attracting chemokine-like protein identified by fold recognition methods. J Immunol. (2006) 176:2069-73. doi: 10.4049/jimmunol.176.4.2069

134. Toka FN, Nfon CK, Dawson H, Estes DM, Golde WT. Activation of porcine natural killer cells and lysis of foot-and-mouth disease virus infected cells. $J$ Interferon Cytokine Res. (2009) 29:179-92. doi: 10.1089/jir.2008.0058

135. Ha H, Debnath $B$, Neamati $N$. Role of the CXCL8-CXCR $1 / 2$ axis in cancer and inflammatory diseases. Theranostics. (2017) 7:154388. doi: 10.7150/thno.15625

136. Arruda-Silva F, Bianchetto-Aguilera F, Gasperini S, Polletti S, Cosentino E, Tamassia N, et al. Human neutrophils produce CCL23 in response to various TLR-agonists and TNF $\alpha$. Front Cell Infect Microbiol. (2017) 7:176. doi: $10.3389 /$ fcimb.2017.00176

137. Chen SC, Mehrad B, Deng JC, Vassileva G, Manfra DJ, et al. Impaired pulmonary host defense in mice lacking expression of the CXC chemokine lungkine. J Immunol. (2001) 166:3362-68. doi: 10.4049/jimmunol.166.5.3362

138. Zhu JJ, Canter JA, Rodriguez LL, Arzt J. A novel bovine CXCL15 gene in the GRO chemokine gene cluster. Vet Immunol Immunopathol. (2019) 10:109990. doi: 10.1016/j.vetimm.2019.1 09990

139. Biswal JK, Ranjan R, Subramaniam S, Mohapatra JK, Patidar S, Sharma MK, et al. Genetic and antigenic variation of foot-and-mouth disease virus during persistent infection in naturally infected cattle and Asian buffalo in India. PLoS ONE. (2019) 14:e0214832. doi: 10.1371/journal.pone.0214832

140. Tecchio C, Cassatella MA. Neutrophil-derived chemokines on the road to immunity. Semin Immunol. (2016) 28:11928. doi: 10.1016/j.smim.2016.04.003

141. Tamassia N, Bianchetto-Aguilera F, Arruda-Silva F, Gardiman E, Gasperini S, et al. Cytokine production by human neutrophils: revisiting the "dark side of the moon". Eur J Clin Invest. (2018) 48 (Suppl. 2):e12952. doi: 10.1111/eci.12952

142. Stegelmeier AA, van Vloten JP, Mould RC, Klafuric EM, Minott JA, Wootton SK, et al. Myeloid cells during viral infections and inflammation. Viruses. (2019) 11:20168. doi: 10.3390/v11020168

143. Schönrich G, Raftery MJ. Neutrophil extracellular traps go viral. Front Immunol. (2016) 7:366-73. doi: 10.3389/fimmu.2016. 00366

144. Hu S, Liu X, Gao Y, Zhou R, Wei M, Dong J, et al. Hepatitis B virus inhibits neutrophil extracellular trap release by modulating reactive oxygen species production and autophagy. J Immunol. (2019) 202:80515. doi: 10.4049/jimmunol.1800871

145. Saitoh T, Komano J, Saitoh Y, Misawa T, Takahama M, Kozaki T, et al. Neutrophil extracellular traps mediate a host defense response to human immunodeficiency virus-1. Cell Host Microbe. (2012) 12:10916. doi: 10.1016/j.chom.2012.05.015
146. González-Alvaro I, Domínguez-Jiménez C, Ortiz AM, Núñez-González V, Roda-Navarro P, Fernández-Ruiz E, et al. Interleukin-15 and interferongamma participate in the cross-talk between natural killer and monocytic cells required for tumor necrosis factor production. Arthritis Res Ther. (2006) 8:R88. doi: 10.1186/ar1955

147. Sträter J, Möller P. TRAIL and viral infection. Vitam Horm. (2004) 67:25774. doi: 10.1016/S0083-6729(04)67014-2

148. Xiao P, Wan X, Cui B, Liu Y, Qiu C, Rong J, et al. Interleukin 33 in tumor microenvironment is crucial for the accumulation and function of myeloid-derived suppressor cells. Oncoimmunology. (2015) 5:e1063772. doi: 10.1080/2162402X.2015.1063772

149. Schiering C, Krausgruber T, Chomka A, Fröhlich A, Adelmann K, Wohlfert EA, et al. The alarmin IL-33 promotes regulatory T-cell function in the intestine. Nature. (2014) 513:564-8. doi: 10.1038/nature 13577

150. Lei $\mathrm{T}$, Jie $\mathrm{C}$, Dandan $\mathrm{X}$, Zhongming $\mathrm{X}$, Bing $\mathrm{Y}$, Ying $\mathrm{T}$, et al. IL-33-induced alternatively activated macrophage attenuates the development of TNBS-induced colitis. Oncotarget. (2017) 8:27704-14. doi: 10.18632/oncotarget.15984

151. Lynch JP, Werder RB, Simpson J, Loh Z, Zhang V, Haque A, et al. Aeroallergen-induced IL-33 predisposes to respiratory virus-induced asthma by dampening antiviral immunity. J Allergy Clin Immunol. (2016) 138:132637. doi: 10.1016/j.jaci.2016.02.039

152. Ishihara Y, Haarmann-Stemmann T, Kado NY, Vogel CFA. Interleukin 33 expression induced by aryl hydrocarbon receptor in macrophages. Toxicol Sci. (2019) 170:404-14. doi: 10.1093/toxsci/kfz114

153. Gutiérrez-Vázquez C, Quintana FJ. Regulation of the immune response by the aryl hydrocarbon receptor. Immunity. (2018) 48:19-33. doi: 10.1016/j.immuni.2017.12.012

154. Sánchez-Díaz R, Blanco-Dominguez R, Lasarte S, Tsilingiri K, Martín-Gayo E, Linillos-Pradillo B, et al. Thymus-derived regulatory $\mathrm{T}$ cell development is regulated by C-type lectin-mediated BIC/MicroRNA 155 expression. Mol Cell Biol. (2017) 37:e00341-16. doi: 10.1128/MCB.00341-16

155. Sekar D, Hahn C, Brüne B, Roberts E, Weigert A. Apoptotic tumor cells induce IL-27 release from human DCs to activate Treg cells that express CD69 and attenuate cytotoxicity. Eur J Immunol. (2012) 42:158598. doi: 10.1002/eji.201142093

156. Yu L, Yang F, Zhang F, Guo D, Li L, Wang X, et al. CD69 enhances immunosuppressive function of regulatory $\mathrm{T}$-cells and attenuates colitis by prompting IL-10 production. Cell Death Dis. (2018) 9:905. doi: 10.1038/s41419-018-0927-9

157. Cibrián D, Sánchez-Madrid F. CD69: from activation marker to metabolic gatekeeper. Eur J Immunol. (2017) 47:946-53. doi: 10.1002/eji.201646837

158. Stelma F, de Niet A, Sinnige MJ, van Dort KA, van Gisbergen KPJM, Verheij $J$ et al. Human intrahepatic CD69 + CD8 + T cells have a tissue resident memory T cell phenotype with reduced cytolytic capacity. Sci Rep. (2017) 7:6172. doi: 10.1038/s41598-017-06352-3

159. Jeong SP, Kang JA, Park SG. Intestinal intraepithelial TCR $\gamma \delta$ ? T cells are activated by normal commensal bacteria. J Microbiol. (2012) 50:83741. doi: 10.1007/s12275-012-2468-8

160. Radulovic K, Manta C, Rossini V, Holzmann K, Kestler HA, Wegenka UM, et al. CD69 regulates type I IFN-induced tolerogenic signals to mucosal CD4 T cells that attenuate their colitogenic potential. J Immunol. (2012) 188:2001-13. doi: 10.4049/jimmunol.1100765

161. Saldanha-Araujo F, Haddad R, Farias KC, Souza Ade P, Palma PV, Araujo AG, et al. Mesenchymal stem cells promote the sustained expression of CD69 on activated T lymphocytes: roles of canonical and non-canonical NF-кB signalling. J Cell Mol Med. (2012) 16:123244. doi: 10.1111/j.1582-4934.2011.01391.x

162. Song X, He X, Li X, Qian Y. The roles and functional mechanisms of interleukin-17 family cytokines in mucosal immunity. Cell Mol Immunol. (2016) 13:418-31. doi: 10.1038/cmi.2015.105

163. Amatya N, Garg AV, Gaffen SL. IL-17 Signaling: The Yin and the Yang. Trends Immunol. (2017) 38:310-22. doi: 10.1016/j.it.2017.01.006

164. Chen K, Eddens T, Trevejo-Nunez G, Way EE, Elsegeiny W, Ricks DM, et al. IL-17 Receptor signaling in the lung epithelium is required for mucosal chemokine gradients and pulmonary host defense against K. pneumoniae. Cell Host Microbe. (2016) 20:596-605. doi: 10.1016/j.chom.2016.10.003 
165. Sun D, Novotny M, Bulek K, Liu C, Li X, Hamilton T. Treatment with IL-17 prolongs the half-life of chemokine CXCL1 mRNA via the adaptor TRAF5 and the splicing-regulatory factor SF2 (ASF). Nat Immunol. (2011) 12:853-60. doi: 10.1038/ni.2081

166. Herjan T, Yao P, Qian W, Li X, Liu C, Bulek K, et al. HuR is required for IL-17induced Act1-mediated CXCL1 and CXCL5 mRNA stabilization. J Immunol. (2013) 191:640-9. doi: 10.4049/jimmunol.1203315

167. Schmitz JM, McCracken VJ, Dimmitt RA, Lorenz RG. Expression of CXCL15 (Lungkine) in murine gastrointestinal, urogenital, endocrine organs. J Histochem Cytochem. (2007) 55:515-24. doi: 10.1369/jhc.6A712 1.2007

168. Abel S, Hundhausen C, Mentlein R, Schulte A, Berkhout TA, Broadway $\mathrm{N}$, et al. The transmembrane CXC-chemokine ligand 16 is induced by IFN-gamma and TNF-alpha and shed by the activity of the disintegrin-like metalloproteinase ADAM10. J Immunol. (2004) 172:636272. doi: $10.4049 /$ jimmunol.172.10.6362

Conflict of Interest: The authors declare that the research was conducted in the absence of any commercial or financial relationships that could be construed as a potential conflict of interest.

Copyright $\odot 2020 \mathrm{Zhu}$, Stenfeldt, Bishop, Canter, Eschbaumer, Rodriguez and Arzt. This is an open-access article distributed under the terms of the Creative Commons Attribution License (CC BY). The use, distribution or reproduction in other forums is permitted, provided the original author(s) and the copyright owner(s) are credited and that the original publication in this journal is cited, in accordance with accepted academic practice. No use, distribution or reproduction is permitted which does not comply with these terms. 